
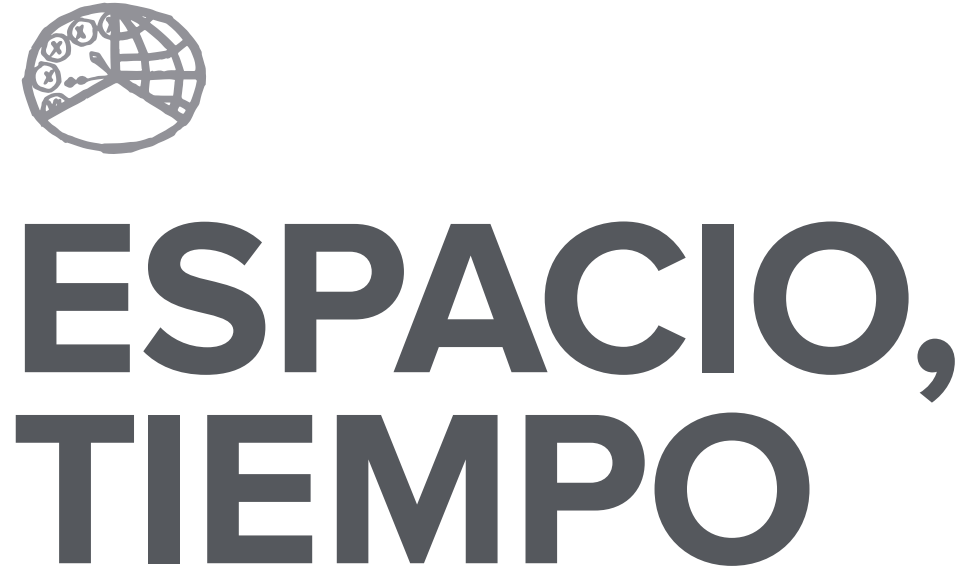

AÑO 2019

ISSN 0214-9745

E-ISSN 2340-1362
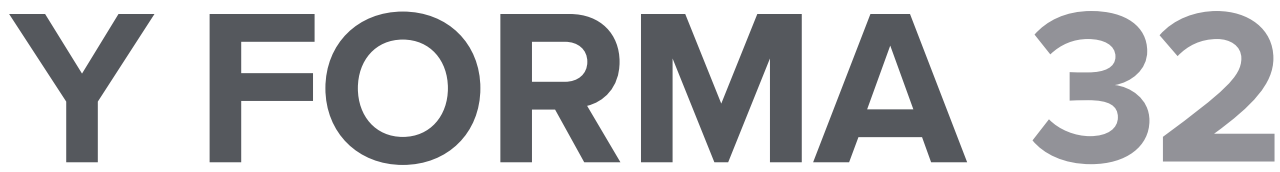

SERIE III HISTORIA MEDIEVAL

REVISTA DE LA FACULTAD DE GEOGRAFÍA E HISTORIA

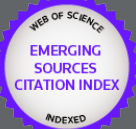





\section{ARTÍCULOS · ARTICLES}





\title{
LA IGLESIA DE MALLORCA Y \\ LA REDENCIÓN DE CAUTIVOS \\ EN LA BAJA EDAD MEDIA
}

\section{THE CHURCH OF MAJORCA AND THE RANSOM OF CAPTIVES DURING THE LATE MIDDLE AGES}

\author{
Albert Cassanyes Roig ${ }^{1}$ \\ Recepción: 2018/11/12 - Comunicación de observaciones de evaluadores: 2019/02/15 . \\ Aceptación: 2019/03/18 \\ DOI: http://dx.doi.org/10.5944/etfiii.32.2019.23040
}

\section{Resumen ${ }^{2}$}

El presente artículo es un primer estudio del rol de la Iglesia en la redención de los cautivos cristianos que se hallaban bajo el yugo de los musulmanes. La tarea de las órdenes redentoristas - trinitarios y mercedarios- en este ámbito fue muy significativa. Menos conocida es la intervención de la catedral, a veces junto a las autoridades municipales. En ambos casos, las limosnas constituían la principal fuente de ingresos, de modo que el rescate era posible gracias a la caridad de los vecinos. El artículo se centra en el ejemplo de la diócesis de Mallorca, un territorio abocado al mar, cuyos habitantes eran frecuentemente capturados. A partir de una serie de registros de subsidios de mediados del siglo xv, se pueden conocer algunos rasgos de los cautivos, la vulnerabilidad en la que quedaban sus familias y el comportamiento de los responsables de la distribución de las limosnas entre las personas a rescatar.

\section{Palabras clave}

Cautivos; limosnas; mar Mediterráneo; órdenes redentoristas; redención de cautivos.

\section{Abstract}

This paper analyses the role of the Church in the ransom of Christian captives who fell under Muslim control. The role of the ransoming orders-Trinitarians

1. Universitat de Lleida. C.e.: albert.cassanyes@historia.udl.cat

2. El presente artículo se enmarca en el proyecto «Expresividad, sentimiento y emoción (siglos XII-XV)» (HAR201675028-P), financiado por el Ministerio de Economía y Competitividad. 
and Mercedarians - in the ransoming process was highly significant. Less known is the intervention of the cathedral chapter, often working side by side with the municipal authorities. In both cases, alms were the most important source of income; the charity of their neighbors made a captive's ransom possible. This paper focuses on the example of the Diocese of Majorca, a territory exposed to the sea, whose inhabitants were frequently captured. Based on some midfifteenth century registers of subsidies it is possible to know some of the individual characteristics of the captives, the vulnerability of their families, and the behavior of the responsible persons who distributed the charitable money among the captives and their families.

\section{Keywords}

Captives; Alms; Mediterranean Sea; Ransoming Orders; Captives' Ransom. 
EL MEDITERRÁNEO bajomedieval era una frontera entre la Cristiandad y el Islam³. Piratas y corsarios infestaban las aguas del antiguo Mare Nostrum y convertían las travesías en peligrosos viajes en los que el riesgo de ser capturado y conducido al norte de África era elevado ${ }^{4}$. Pescadores, tripulaciones de barcos mercantes o de guerra y habitantes costeños constituían las presas más habituales 5 . Pero el cautiverio no era un estado permanente, ya que era posible recuperar la libertad a cambio de un considerable monto económico ${ }^{6}$. Los cautivos cristianos, entonces, pasaban a depender tanto de sus familiares $u$ otros allegados, encargados de reunir el dinero, como de la caridad de los demás para lograr su liberación ${ }^{7}$. No en vano, la redención de los prisioneros era una de las siete obras corporales de misericordia que se enseñaban en el catecismo, y la caridad por sí misma era considerada una de las virtudes teologales ${ }^{8}$. Las limosnas, manifestaciones de la práctica caritativa, se vieron fomentadas por el conocimiento de los tormentos que los prisioneros padecían en las tierras islámicas, según el imaginario popular.

A pesar de que existieron instituciones redentoristas de carácter laico ${ }^{\mathrm{Io}}$, el protagonismo en la liberación de los cautivos recayó en la lglesia, y, más concretamente, en las llamadas órdenes redentoristas. Las páginas que siguen pretenden ser una aproximación a los diferentes mecanismos que la Iglesia tenía para redimir a los cristianos que eran aprisionados por los musulmanes. Se ha querido acotar el ámbito de estudio a la diócesis de Mallorca, que durante todo el Medioevo también incluía la isla de Menorca. Las islas Baleares eran un territorio dedicado enteramente al mar debido a su situación estratégica en medio del Mediterráneo occidental ${ }^{\text {II }}$. Sus habitantes y todos aquellos que tenían que navegar hacia o desde

3. Fernández de Córdoba Miralles, Álvaro: «Sobre el encuentro del Cristianismo con el Islam en el Mediterráneo occidental», Anuario de Historia de la Iglesia, 16 (2007), p. 151. Para la cotidianidad - no siempre conflictiva- en el espacio fronterizo, véase Rodríguez MolinA, José: La vida de moros y cristianos en la frontera. Alcalá la Real, Alcalá, 2007.

4. La historiografía hispánica distingue entre «cautivos» - apresados por personas de religión diferente- y «prisioneros» - apresados por gente de la misma religión que el capturado. En este trabajo se usan los dos términos como sinónimos a fin de no repetir de forma asidua el término «cautivo».

5. Brodman, James William: «Captives or Prisoners: Society and Obligation in Medieval Iberia», Anuario de Historia de la Iglesia, 20 (2011), p. 203.

6. Este artículo toma la definición de cautivo que se propone en CIPOLLONE, Giulio: «L'Ordo Trinitatis et captivorum. II suo insediamento nelle Baleari (XIII-XIV)», en XIII Congrés d'Història de la Corona d'Aragó. Palma de Mallorca, 27 setembre-1 octubre 1987. Palma, Institut d'Estudis Baleàrics, 1989, III, p. 38: (...) colui che è stato sottratto con violenza al complesso di valori che appartengono a lui e al suo gruppo e società, e che non è ancora reso servus. Sobre la definición de «cautivo» y la diferencia entre «cautividad» y «esclavitud», véase el completo análisis de DíAz BORRÁs, Andrés: El miedo al Mediterráneo: la caridad popular valenciana y la redención de cautivos bajo poder musulmán, 1323-1539. Barcelona, Consejo Superior de Investigaciones Científicas, Institución Milá y Fontanals, 2001, pp. 19-28.

7. Brodman, James William: «Captives or Prisoners...», pp. 206.

8. TORRES JIMÉNEZ, Raquel: «Reflexiones sobre religiosidad medieval: el concepto de caridad en la espiritualidad laica, del amor a Dios al amor a los pobres, del mundo rural al humanismo», Cuadernos de Estudios Manchegos, 36 (2011), pp. 167-168.

9. SAlrach I Marès, Josep Maria: «Els orígens de l'Orde de la Mercè i el rescat de captius. Les Croades i l'exercici de la caritat a l'Edat Mitjana», Acta Historica et Archaeologica Mediaevalia, 9 (1988), pp. 189-190.

10. Cipollone, Giulio: «L'Ordo Trinitatis et captivorum...», p. 38; BrodmAN, James William: Charity \& Religion in Medieval Europe. Washington D.C., The Catholic University of America Press, 2009, pp. 41-44.

11. Morro Veny, Guillem: La marina medieval mallorquina (1250-1450). Palma, Documenta Balear, 2009 , p. 23. 
ellas debían afrontar el riesgo de ser capturados. Por este motivo, la diócesis marítima constituye un caso de estudio de gran interés.

No abundan los documentos que traten ampliamente sobre la redención de cautivos, y también hay que lamentar la ausencia de series archivísticas que reúnan los registros en los que se anotaban los subsidios a ellos otorgados. Dos listados, datados en I45I y I454, fueron hallados en el interior de dos volúmenes de la serie «Extraordinarios de la Universidad», en los que se anotaban las resoluciones que tomaban las autoridades municipales y regnícolas sobre temas muy diversos ${ }^{\mathrm{I2}}$. La verdad es que estos encuentros son bastante inhabituales, puesto que listas similares no abundan en los demás libros de la misma serie y cronología. Más raro es el caso de un tomo del Archivo Capitular de Mallorca en el que se registró la concesión de subsidios a varias personas capturadas por los musulmanes entre los años I44I y I477, con lagunas ${ }^{13}$. A pesar de que una mano moderna indicó con lápiz que se trataba de un libro de redención de cautivos, se halla inserido en la serie documental de «Fábrica», que reúne los volúmenes en los que se recogen los ingresos y los gastos del organismo encargado de la construcción y del mantenimiento de la catedral. Es probable que el canónigo Josep Miralles, quien catalogó el archivo a inicios del siglo xx, confundiera las entradas procedentes de los bacines para los cautivos con las cantidades que venían de las cajas de colecta para la obra catedralicia ${ }^{\mathrm{I}}$. Cabe indicar que el volumen es el único de estas características que se ha hallado en el Archivo Capitular, aunque no se puede descartar que haya más registros erróneamente catalogados en otras series.

\section{LA REDENCIÓN DE CAUTIVOS: UNA NECESIDAD CRISTIANA}

El apresamiento de cristianos constituyó una verdadera lacra para los habitantes de la diócesis de Mallorca, que no solo se exponían en sus viajes, sino que también sus casas, no lejanas al mar, eran potenciales objetivos de los musulmanes ${ }^{15}$. En

\footnotetext{
12. Archivo del Reino de Mallorca (ARM), Archivo Histórico (AH), Extraordinarios de la Universidad (EU) 9, f. 125r-v; y ARM, AH, EU 10, ff. 119r-120v.

13. Archivo Capitular de Mallorca (ACM), 1731. Este registro fue presentado, sin ningún estudio que lo acompañara, en ROSSElló VAQUer, Ramon, y Bover Pujol, Jaume: «Captius cristians de Mallorca al nord d'Àfrica. Segle XV. Una relació», en García MARín, Jesús (coord.): América y Mallorca. Del predescubrimiento hasta el siglo Xx. Miscelánea humanística, I. Palma, Ajuntament de Palma, 1991, pp. 43-46.

14. Miralles Sbert, José: Catálogo del Archivo Capitular de Mallorca, vol. 1. Palma, Imprenta «mossèn Alcover», 1936 , p. 334 .

15. Los ejemplos son abundantes en la mayoría de villas costeras. Fue el caso del pequeño pueblo de s'Arracó (Andratx), que fue asaltado a finales del siglo xiv por los corsarios renegados Pere Fuster y Antoni Jordà. FerRER MALLOL, Maria Teresa: «El castigo de los corsarios en el mundo mediterráneo medieval», en GUIANCE, Ariel, y UBIERNA, Pablo (coords.): Sociedad y memoria en la Edad Media. Estudios en homenaje de Nilda Guglielmi. Buenos Aires, Consejo Nacional de Investigaciones Científicas y Técnicas, Instituto Multidisciplinario de Historia y Ciencias Humanas, 2005, p. 124. Las expediciones corsarias equivaldrían a las cabalgadas de la frontera, aunque con la peculiaridad de que los asaltantes
} 
un momento indeterminado, los corsarios penetraron en Menorca y se llevaron a una veintena de personas, la mayoría de ellas de Mahón, según la relación enviada a la isla vecina:

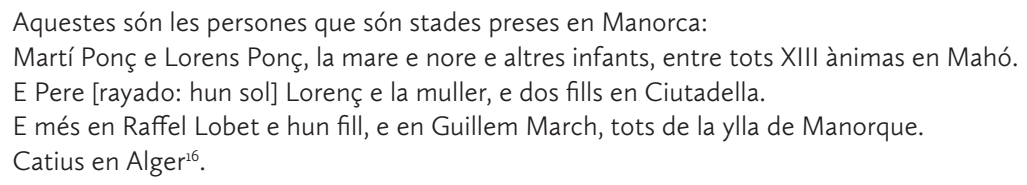

El motivo de esta lista no era otro que informar de la identidad y del paradero -Argel- de los cautivos, unos datos que eran fundamentales para iniciar el proceso que se esperaba culminar con su feliz redención. Similar fue el caso del cautivo Miquel Sicília, cuya mujer se puso a disposición de las autoridades pertinentes para informarles sobre su marido:

Senyor. Recort vos dia d'en Miquell Cicília, per lo qual la muller demana e és presta de dar informació.

És catiu Atenes. Onoffre ${ }^{17}$.

Precisamente, eran los parientes del cristiano apresado quienes solían iniciar y protagonizar el procedimiento; ellos eran los encargados de llevar a cabo las gestiones requeridas para lograr su redención. La misión principal, y la que requería más esfuerzo y dedicación, consistía en reunir las cantidades exigidas para el rescate, que frecuentemente excedían sobremanera los ingresos familiares y comprometían la situación económica doméstica durante años o generaciones ${ }^{18}$. Las opciones más rápidas para acumular el dinero eran proceder a solicitar préstamos o subastar los bienes ${ }^{19}$. Sin embargo, lo más habitual fue que se solicitara a las autoridades municipales y episcopales una autorización para pedir limosna pública y temporalmente para su pariente ${ }^{20}$. Las limosnas también nutrían los bacines que había repartidos por todas las parroquias del obispado. Las cantidades que se obtenían en ellos eran luego distribuidas por una comisión integrada por los jurados, el obispo y el Cabildo, como se comentará más adelante. Estos subsidios eran importantes, especialmente si el cautivo era el cabeza de familia

se movían mediante transportes marítimos. Calderón OrTEGA, José Manuel, y Díaz GonzÁlez, Francisco Javier: Vae Victis: cautivos y prisioneros en la Edad Media Hispánica. Alcalá de Henares, Universidad de Alcalá, 2012, pp. 38-43.

16. ACM, 1731, sf.

17. ACM, 1731, sf.

18. RodRIGUEZ, Jarbel: «Financing a Captive's Ransom in Late Medieval Aragon», Medieval Encounters, 9/1 (2003), pp. 166-170; Brodman, James William: «Captives or Prisoners...», p. 214; Rodríguez MolinA, José: op. cit. p. 86; Calderón Ortega, José Manuel, y Díaz González, Francisco Javier: Vae Victis..., pp. $291-293$.

19. Pujol, Margalida: «L'esclavitud en el Regne de Mallorca durant el govern del Rei Martí l. 1396-1410», Bolletí de la Societat Arqueològica Lul.liana, 52 (1996), p. 138.

20. Brodman, James William: «Community, Identity and the Redemption of Captives: Comparative Perspectives across the Mediterranean», Anuario de Estudios Medievales, 36/1 (2006), pp. 251-252; SiERra VALENTí, Eduard: «Captius de sarraïns. Llicències per a demanar caritat del bisbes de Girona (1376-1415)», Anuario de Estudios Medievales, $38 / 1$ (2008), pp. 390-419. 
y no había nadie que lo pudiera reemplazar en el trabajo, lo que implicaba la imposibilidad de reunir el dinero necesario para pagar el rescate. Este fue el caso de doña Anneta, que solo tenía cinco hijos pequeños, y que apeló directamente a los jurados y al Cabildo:

\begin{abstract}
Senyors,
Molt magnífichs, molt suplica a las magnificèncias vostres la dona Anneta, muller d'en Pedro Muyoz, que de las almoynes que's tenan a pertir li'n vullau donar per lo rescat de son marit, que és catiu en Barbaria e stà en perill de negar la sancta fe catòlica e no té esperansa sinó de nostre Senyor e de las caritats de las magnificèncias vostres, perquè no té pare ni germans que ni per ell treballar puscan, sinó la pobre de sa muller que té a nidar sinch infans de poca adat e no té de què sinó de caritats nostre Senyor li dóna per medi de algunes virtuoses personas. Per sò los suplica vullan mirar la gran pobresa que aquest hom té e la necessitat que passen aquells patits infans ${ }^{21}$.
\end{abstract}

Como se puede observar, la mujer explicaba que necesitaba este dinero debido a que el cautivo, Pedro Muñoz, no tenía ningún pariente varón que pudiera trabajar para reunir el monto exigido para el rescate. Más bien al contrario, sus únicos familiares eran su mujer y sus cinco hijos, todos de escasa edad, que solo podían sobrevivir gracias a las limosnas y a la ayuda de otras personas. Además, la redención acuciaba, puesto que la posibilidad de renegar planeaba sobre el cautivo ${ }^{22}$.

Pedro Muñoz no disponía de padres o hermanos que pudieran juntar el dinero, pero sí de una mujer que no dudó en pedir auxilio a las autoridades municipales y eclesiásticas. En una posición quizá más vulnerable se encontraba Miquel Comidan, un cautivo en Alger que no té amich ni parent, sinó mara, la qual stà en casa del honorable mossèn Pere Borrassà per amor de Déu. Comidan había sido capturado por los musulmanes en Valencia, y su único contacto en la isla $-y$, por tanto, quien tenía que hacerse cargo de su redención- era su madre, que se encontraba en situación de gran necesidad ${ }^{23}$. Tanto el caso de Miquel Comidan como de Pedro Muñoz son un ejemplo clarísimo de la extrema fragilidad en la que quedaban tanto los cautivos como sus familiares, así como el esfuerzo que estos tenían que realizar para conseguir reunir el dinero para la anhelada liberación.

A pesar de ello, como afirma Brodman, la redención de los cautivos era un acto comunitario. Los cristianos que aportaban las limosnas - a veces animados por la concesión de una indulgencia a cambio- ${ }^{24}$ las ofrecían sin saber a quién se destinaría aquel dinero. Generalmente, poco importaba si el rescatado era un conocido o un completo extraño: era un acto de caridad para redimir a un miembro de la comunidad. A pesar de que la práctica caritativa era un precepto recogido en el Antiguo y en el Nuevo Testamento y defendido por los padres de la Iglesia,

21. ACM, Papeles y cuadernos sueltos, 16.298, sf.

22. Calderón Ortega, José Manuel, y Díaz González, Francisco Javier: Vae Victis..., pp. 281-286. La apostasía era más frecuente entre las mujeres y los niños, según Rodríguez MolinA, José: op. cit. p. 85.

23. ACM, 1731, sf.

24. BROdmAn, James William: «Captives or Prisoners...», p. 215. 
fue a partir del siglo xil cuando se documenta un auge de la misma, coincidiendo con el desarrollo urbano y el incremento de la brecha entre ricos y pobres ${ }^{25}$. Fue, por ejemplo, en este momento cuando se multiplicaron las fundaciones de hospitales ${ }^{26}$. Sin embargo, la forma más rápida y sencilla de realizar la virtud cristiana de la caridad era llevar a cabo la obra de misericordia de socorrer a pobres y necesitados mediante limosnas. Asimismo, la Baja Edad Media también significó la institucionalización de la caridad, de modo que las instituciones - especialmente las municipales - obtuvieron un protagonismo cada vez mayor en ella ${ }^{27}$. Este hecho se puede observar en el ámbito de la redención de los cautivos, puesto que se tomaron medidas para facilitar su rescate. Por ejemplo, en las villas castellanas se aprobaron disposiciones de carácter económico, de salvaguardia de los bienes de los cautivos o de regulación de exeas y alfaqueques ${ }^{28}$, esto es intermediarios para lograr la redención de los cristianos prisioneros ${ }^{29}$. Iniciativas similares se documentan igualmente en la Corona de Aragón. Ya el conde Ramón Berenguer envió algunos mercaderes judíos a tierras islámicas para negociar la redención de los cautivos ${ }^{30}$. Por su parte, Alfonso el Batallador otorgó a Calatayud un fuero por el que los padres de un cristiano apresado podían disponer de cualquier esclavo musulmán de la villa para intercambiarlo por su hijo ${ }^{31}$. Exeas y alfaqueques también actuaron en los dominios del rey de Aragón ${ }^{32}$.

En los casos más afortunados - los menos-, la liberación de los cautivos suponía una realidad. Tras el pago del rescate, los redimidos eran enviados a tierras cristianas en navíos particulares. Por ejemplo, en I4I2 veintiocho cautivos rescatados por los mercedarios llegaron a Mallorca a bordo de la navecilla de un barcelonés apellidado Riera33. Medio siglo más tarde, en I465, Jaume Vicens regresó a la isla en la galera de Ferrando Valentí3 ${ }^{4}$. La verdad es que los mercaderes se fueron involucrando de cada vez más en la redención de los cautivos, ya que

25. Idem, p. 206.

26. Conejo dA PenA, Antoni: Assistència i hospitalitat a l'edat mitjana. L'arquitectura del hospitals catalans: del gòtic al primer renaixement. Barcelona, Universitat de Barcelona, (tesis doctoral inédita), 2002, p. 75-76; BRODMAN, James William: Charity \& Religion..., pp. 55-61.

27. TORRES JIMÉNEZ, Raquel: op. cit. p. 166.

28. Véanse Díaz Borrás, Andrés: op. cit. pp. 61-72; Calderón OrtegA, José Manuel, y Díaz González, Francisco Javier: «El rescate de prisioneros y cautivos durante la Edad Media hispánica. Aproximación a su estudio», Historia. Instituciones. Documentos, 38 (2011), pp. 26-28; CALderón OrTegA, José Manuel, y Díaz González, Francisco Javier: Vae Victis..., pp. 163-168, y 234-263.

29. Idem, pp. 19-23; BRODMAN, James William: «Community, Identity...», pp. 243-244; Brodman, James William: «Captives or Prisoners...», p. 207.

30. Idem, p. 209.

31. Rodriguez, Jarbel: Captives and Their Saviors in the Medieval Crown of Aragon. Washington D.C., The Catholic University of America Press, 2007, p. xiv. Para los intercambios de cautivos por esclavos, véase FerRer MALLOL, Maria Teresa: «La redempció de captius a la Corona catalano-aragonesa (segle XIv)», Anuario de Estudios Medievales, 15 (1985), pp. $244-247$.

32. Idem, pp. 262-266.

33. PASCUAL, Eusebio: «Redención y ostentación de cautivos. Siglos XIII y XV», Bolletí de la Societat Arqueològica Lul.liana, 6 (1895), p. 123.

34. ACM, 1731, f. 56v. Sobre Ferrando Valentí, véase BARCeló CRespí, Maria, y EnSEnYAT Pujol, Gabriel: Ferrando Valentí i la seva família. Barcelona, Universitat de les Illes Balears, Abadia de Montserrat, 1996. 
sus continuos viajes a los territorios islámicos los ponía en contacto con los prisioneros y los convertían en perfectos negociadores e, incluso, exeas ${ }^{35}$. Por esto motivo, no debe sorprender tampoco que fueran los medios más idóneos para conducir a los redentores a tierras islámicas ${ }^{36}$ y devolver los rescatados a los dominios de la cristiandad.

A veces, los cautivos podían ser liberados mediante pactos políticos como consecuencia de una tregua o de un acuerdo de intercambio de prisioneros ${ }^{37}$. La redención de los cristianos apresados en el norte de África era una prioridad para los soberanos de la Corona de Aragón, que, frecuentemente, la incluyeron en los tratados de paz con los sarracenos ${ }^{38}$. Por ejemplo, en $\mathrm{I} 353$ Pere de Pacs acordó con el rey de Túnez que se devolverían a este último los prisioneros y las mercaderías que la nave de Antoni Arquer había apresado en una expedición de corso. A cambio, los musulmanes deberían liberar a los cristianos cautivos, junto con sus bienes, que fueron apresados cuando viajaban en el leño de Berenguer Gassós ${ }^{3}$. También se dieron casos de liberación de un cautivo para que procurara juntar el dinero necesario para el rescate de otros. Por ejemplo, Bartomeu Fuster fue dejado en libertad para que consiguiera las ochocientas doblas de oro necesarias para la redención de su mujer Romia y de sus hijos, todos ellos apresados en Ibiza $^{40}$.

\section{LAS ÓRDENES REDENTORISTAS: TRINITARIOS Y MERCEDARIOS}

Sin duda alguna, el protagonismo del rescate de los cautivos cristianos recayó en las órdenes redentoristas ${ }^{41}$. Los diferentes reinos medievales habían ido desarrollando varios mecanismos para lograr la redención de sus súbditos prisioneros en manos de los musulmanes, aunque su efectividad no era óptima. La Iglesia tampoco olvidó completamente la obra de misericordia de liberar a los presos, puesto que las órdenes militares se ocuparon de su rescate de forma suplementaria a sus funciones ${ }^{42}$. Sin embargo, no fue hasta finales del siglo xil e inicios del xill cuando

35. Ferrer Mallol, Maria Teresa: «La redempció de captius...», pp. 267-268; Rodriguez, Jarbel: Captives and Their Saviors..., p. xiv; Calderón Ortega, José Manuel, y Díaz González, Francisco Javier: Vae Victis..., p. 263.

36. SANCHO, Pedro Antonio: «Redención de cautivos por los frailes trinitarios», Bolletí de la Societat Arqueològica Lul.liana, 8 (1900), p. 336.

37. Calderón Ortega, José Manuel, y Díaz González, Francisco Javier: Vae Victis..., pp. $217-226$

38. Brodman, James William: «Captives or Prisoners...», pp. 216-219. Algunos ejemplos en Ferrer MalloL, Maria Teresa: «La redempció de captius...», pp. 247-250.

39. Morro VenY, Guillem: op. cit. p. 52.

40. Sierra Valentí, Eduard: op. cit. p. 415-416. Más ejemplos en Ferrer Mallol, Maria Teresa: «La redempció de captius...», pp. 255-256.

41. Además de las órdenes redentoristas, también obispos y algunas órdenes militares ejercieron tareas de rescate de cautivos. SALRACH I MARÈs, Josep Maria: op. cit. pp. 191-192. Sin embargo, para el período que se estudia en este artículo, los prelados habían delegado esta tarea en otros actores, mientras las órdenes militares también tuvieron un rol cada vez menos significativo.

42. Ayala Martínez, Carlos de: «Órdenes militares hispánicas: reglas y expansión geográfica», en García DE 
aparecieron dos órdenes cuyo carisma incluía como prioridad y misión fundamental la redención de los cautivos: los trinitarios y los mercedarios. Las dos órdenes religiosas fueron fundadas con escasos años de diferencia: en II98 Inocencio III - un papa extremadamente preocupado por la suerte de los cristianos capturados por los musulmanes — 43 aprobó la regla de la Orden de la Santísima Trinidad y de la Redención de Cautivos, instaurada por Juan de Mata y Félix de Valois una decena de años antes ${ }^{44}$. Poco después, hacía I2 I8, el catalán Pedro Nolasco creó la Orden Real y Militar de Nuestra Señora de la Merced y de la Redención de Cautivos, que contó con el apoyo de los propios reyes de la Corona de Aragón ${ }^{45}$.

Desde el primer momento, la prioridad de ambas órdenes fue la redención de los cautivos. A este efecto, negociaban con los captores, canalizaban el pago de los rescates y ofrecían ayuda económica a las familias de los prisioneros ${ }^{46}$. Incluso podían llegar a proponer el intercambio del reo por un fraile, que ocuparía el lugar del cautivo hasta que se satisficiera el monto exigido para su liberación ${ }^{47}$. Para pagar las redenciones, la principal actividad de trinitarios y mercedarios era la obtención de recursos, entre los cuales donaciones, legados testamentarios o limosas depositadas en cajas ubicadas en lugares estratégicos, como hornos municipales ${ }^{48}$. Las constituciones de las órdenes redentoristas ya previeron algunas medidas encaminadas al objetivo final de la comunidad. Los trinitarios, por ejemplo, incluyeron en su Regla de II98 la imposición de destinar una tercera parte de los ingresos de la casa trinitaria a la liberación de los cautivos, ya fuera para pagar el rescate, ya fuera para comprar un esclavo pagano o infiel para canjearlo por el cristiano ${ }^{49}$. Sin embargo, en el Capítulo General que la Orden tuvo en la casa-madre de Cerfroid en I429, el tercio de los ingresos se convirtió en una cuota fija que cada casa tenía que pagar ${ }^{50}$.

Cortázar, José Ángel, y Teja, Ramón (dirs.): Los monjes soldados. Los templarios y otras órdenes militares. Aguilar de Campoo, Fundación Santa María la Real, 2004 [1997], p. 74; BroDMAN, James William: «Captives or Prisoners...», p. 212; PorRas ArboledAs, Pedro: «La obligación de rescatar cautivos y la Orden de Santiago (1517-1535)», Hispania Sacra, 69/139 (2017), pp. 195-219. Igualmente importante fue la efímera Orden del Santísimo Redentor, fundada en 1188 por iniciativa de Alfonso el Casto. Ayala Martínez, Carlos de: Las órdenes militares hispánicas en la Edad Media (siglos XII-xv). Madrid, Marcial Pons, La Torre Literaria, 2007, pp. 106-107.

43. BRODMAN, James William: «Captives or Prisoners...», pp. 211-212.

44. Para los trinitarios, véanse Cipollone, Giulio: Studi intorno a Cerfroid, prima casa dell'ordine trinitario (11981429). Roma, Ordinis Trinitarium Institutum Historicum, 1978; CIPOLLONE, Giulio: Cristianità-Islam, cattività eliberazione in nome di Dio. II tempo di Innocenzo III dopo il 1187. Roma: Pontificia Università Gregoriana, 1992.

45. Sobre la Orden de la Merced, véase Brodman, James William: Ransoming Captives in Crusader Spain. The Order of Merced on the Christian-Islamic Frontier. Filadelfia, University of Pennsylvania Press, 1986; RUBINO, Antonio: L'Ordine di Santa Maria della Mercede (1218-1992). Sintesi storica. Roma, Istituto Storico, 1997.

46. Sierra Valentí, Eduard: op. cit. p. 387; Brodman, James William: «Captives or Prisoners...», p. 212.

47. En 1390 el mercader mallorquín Guillem Urgell exigió al provincial de los trinitarios, Bernat Rufaca, que se le rembolsaran las cuarenta y ocho libras que había pagado para rescatar a dos frailes. CIPOLLONE, Giulio: «L'Ordo Trinitatis et captivorum...», p. 42. A pesar de este ejemplo, Brodman considera que los redentoristas no arriesgarían el triunfo de una campaña para rescatar uno o dos cautivos más con un intercambio. BRODMAN, James William: Ransoming Captives..., p. 111-113. De hecho, no se puede asegurar que los dos frailes rescatados por Guillem Urgell hubieran sido realmente aprisionados a cambio de los cautivos cristianos.

48. Brodman, James William: «Community, Identity...», p. 249.

49. ReYnés, Lorenzo: Chrónica de la Provincia del Orden de la Santísima Trinidad Redención de Cautivos. Biblioteca Pública de Palma, ms. 47, ff. 58r-64v. La Regla de 1198 se halla en Archivo Secreto Vaticano, Registros Vaticanos, 4, ff. 126v-128r.

50. BRODMAN, James William: «Community, Identity...», p. 247. 
En cualquier caso, la disposición de la Regla de II98 marcó significativamente a los trinitarios, puesto que los recursos dedicados al rescate no dependieron de la voluntad de los frailes, sino de sus entradas ${ }^{51}$. Por su parte, las constituciones de los mercedarios, que fueron redactadas por el dominico Ramón de Peñafort ${ }^{52}$, centraban claramente la misión de la Orden de la Merced en la redención de los cautivos - un «cuarto voto» de los profesos-, a diferencia de los trinitarios, que también gestionaron hospitales ${ }^{53}$.

Las dos órdenes redentoristas tenían representación en Mallorca ${ }^{54}$. Ambas se establecieron en la isla poco después de la conquista, puesto que constituía una excelente base geográfica desde donde dirigirse hacia el norte de África ${ }^{55}$. Con todo, las fundaciones de las casas redentoristas en la balear mayor están escasamente documentadas, y no solo por la pérdida de sus archivos a raíz de la desamortización: en el siglo xvil el padre Lorenzo Reynés, cronista de la provincia trinitaria de Aragón, ya indicaba que no encontró instrumentos relativos al establecimiento de su Orden en Mallorca ${ }^{56}$. Sin embargo, la llegada de los trinitarios a la isla cuenta con un relato conocido, puesto que se atribuye su venida a la donación de unas casas en la parte baja de la ciudad por parte de doña Constanza de Aragón, hermana del rey Jaime I, que había enviudado de Guillermo Ramón de Montcada, fallecido durante la conquista ${ }^{57}$. Más desconocida es la llegada de los mercedarios ${ }^{58}$ : a pesar de que algunos autores indican que el fundador de la Orden, Pedro Nolasco, acompañó a Jaime I en la conquista de Mallorca y que fundó la casa mercedaria antes de I235 $5^{59}$, el padre Reynés afirma que los frailes de la Merced no fueron autorizados a pasar a la isla hasta $1307^{60}$. Tanto los trinitarios como los mercedarios erigieron también casas en la vecina isla de Menorca: los hijos de Juan de Mata la fundaron en I28 $7^{6 r}$; la casa de la Merced tiene orígenes oscuros — se llegó a afirmar que la creó el propio Pedro Nolasco cuando vino con el rey en I229-, pero ya funcionaba en I29I, puesto que es nombrada en una bula de Nicolás $I^{62}$. La verdad es que es

51. Cipollone, Giulio: «L'Ordo Trinitatis et captivorum...», p. 40.

52. O'Callaghan, Joseph F.: A History of Medieval Spain. Ithaca, Cornell University Press, 1975, p. 497.

53. BRODMAN, James William: «Community, Identity...», p. 248.

54. Barceló Crespí, Maria, y Rosselló Bordoy, Guillem: La ciudad de Mallorca. La vida cotidiana en una ciudad mediterránea medieval. Palma, Lleonard Muntaner, Editor, 2006, pp. 363-374. Para la casa mallorquina de los trinitarios, véase REYNÉs, Lorenzo: op. cit. f. 24 r.

55. CIPOLLONE, Giulio: «L'Ordo Trinitatis et captivorum..., pp. 40-41

56. ReYNÉS, Lorenzo: op. cit. f. zor.

57. Mut i Armengol, Vicente: Historia del Reyno de Mallorca. Mallorca, 1650, pp. 528-529; ReYnÉs, Lorenzo: op. cit. ff. $30 \mathrm{r}-33$ r.

58. La aproximación más reciente a la historia y, sobre todo, a la arquitectura de la casa mercedaria de Mallorca es Nieto Cerdà, Maria Magdalena: «El convent de la Mercè», en BARCeló Crespí, Maria, y Moll Blanes, Isabel (coords.): Abadies, cartoixes, convents i monestirs. Aspectes demogràfics, socioeconòmics i culturals de les comunitats religioses (segles XIII al XIX). Palma, Institut d'Estudis Baleàrics, 2003, pp. 33-56.

59. Mut I Armengol, Vicente: op. cit. pp. 532-533.

6o. REYNÉs, Lorenzo: op. cit. f. 35 r. Reynés confundiría la autorización a los mercedarios para pasar a Mallorca con la autorización a los frailes de la Merced a pedir limosna en Menorca, como se verá.

61. Cipollone, Giulio: «L'Ordo Trinitatis et captivorum...», pp. 42-43.

62. Mut I Armengol, Vicente: op. cit. p. 534. 
posible que los mercedarios se hubieran establecido en Menorca poco después de la conquista de Alfonso el Liberal en I287, pero, cuando la isla pasó al Reino de Mallorca en virtud del tratado de Anagni de i295, Jaime Il de Mallorca confiscaría sus bienes, y no sería hasta 1307 cuando los frailes de la Merced serían autorizados a pedir limosna entre los menorquines ${ }^{63}$.

Con el objetivo de reunir las cantidades necesarias para lograr la redención de los cautivos, los trinitarios y los mercedarios de Mallorca pedían limosnas. Además, según Vicente Mut, la Orden de la Santísima Trinidad también centralizó en la isla los montos que se recaudaban en las provincias de Inglaterra, Escocia, Hibernia - Irlanda-, Dania - Dinamarca-, Holanda y Francia ${ }^{64}$. Por otro lado, algunas personas podían acordar con los frailes el rescate de un determinado individuo, procediendo a entregar el monto del rescate correspondiente cuando se anunciaba públicamente una nueva expedición redentorista ${ }^{65}$. La utilización de este dinero en la redención de los cautivos se realizaba a través de varias vías. Sin duda, la más conocida y vistosa era el traslado personal de los frailes a tierras islámicas - principalmente, al norte de África y al Reino de Granada — para abonar los rescates de los cristianos y devolverlos a casa. De hecho, ya en I385 se documenta un viaje de los trinitarios de Mallorca a Bugía para rescatar algunos cristianos ${ }^{66}$. Sin embargo, también se podía optar por entregar el dinero a las familias de los cautivos a modo de subsidio. Así, eran los propios parientes de los presos quienes gestionaban el rescate. En otras ocasiones, el monto era entregado a un tercero - generalmente un mercader que viajaba a los territorios islámicos- para que se encargara del pago ${ }^{67}$.

El número de cautivos que las órdenes redentoristas lograban rescatar en una misión es difícil de determinar. Algunos documentos proporcionan este dato. Brodman, por ejemplo, al hablar sobre las redenciones protagonizadas por mercedarios, menciona la ayuda o el rescate de sesenta y dos y cincuenta cautivos en 1366 y i388, respectivamente ${ }^{68}$. Por otro lado, en una operación redentorista que tuvo lugar en I4I2, los mercedarios liberaron a un total de veintiocho cristianos que habían sido hechos cautivos en varias plazas del norte de África ${ }^{69}$. Se trata, pues, de expediciones que supusieron la redención de medio centenar de personas. En cambio, las crónicas de las órdenes religiosas tienden a presentar un número de cautivos rescatados que resulta, al menos, sospechoso. Por ejemplo, en una ocasión el ya mencionado Lorenzo Reynés indica que los frailes de la Orden de la Santísima

63. SASTRE MOLL, Jaime: «Los pobres y su asistencia hospitalaria en Menorca. La captación de limosnas por órdenes religiosas (s. XIV)», Bolletí de la Societat Arqueològica Lul.liana, 57 (2001), p. 56.

64. Mut i Armengol, Vicente: op. cit. p. 529.

65. Véase SANCHO, Pedro Antonio: op. cit. p. 336.

66. Cipollone, Giulio: «L'Ordo Trinitatis et captivorum...», p. 42

67. BRODMAN, James William: «Community, Identity...», pp. 248-249.

68. Idem, p. 250.

69. Pascual, Eusebio: op. cit. pp. 123-124. 
Trinidad liberaron a mil quinientos veinte cautivos en catorce redenciones que tuvieron lugar en una cronología de doce años; $;^{70}$ en otras palabras, se rescataría una media de ciento ocho cautivos en cada actuación. Este número parece exagerado, sobre todo si se compara con las cantidades proporcionadas por el mercedario Gabriel Téllez, según el cual los frailes de la Merced redimieron siete mil personas en un periodo de cien años, esto es, setenta personas anuales ${ }^{71}$. No se puede argumentar que los trinitarios fueran más exitosos que los mercedarios, puesto que fueron estos últimos quienes tuvieron la primacía en la Corona de Aragón ${ }^{72}$. La causa se tendría que buscar más bien en el hecho que las crónicas de los redentoristas persiguen el ensalzamiento de la orden correspondiente, y, por este motivo, podría haber una tendencia a exagerar el número de cristianos redimidos ${ }^{73}$. Igualmente crecidos serían los números difundidos a través de otras historias y crónicas no necesariamente vinculadas a las órdenes. Por ejemplo, en la Historia del Reyno de Mallorca de Vicente Mut, el autor refiere que el 4 de abril de I306 dos trinitarios mallorquines rescataron a un total de quinientos noventa cautivos en Argel ${ }^{74}$. Mut lo justifica con el supuesto que Mallorca recibía la recaudación de seis provincias, pero, a pesar de ello, el total de rescatados parece excesivo.

Los mercedarios - aunque también los trinitarios - usaron los rescates que realizaban como instrumento de propaganda para lograr más limosnas. Así, los cautivos redimidos tenían que viajar con los frailes redentoristas durante un año y un día ${ }^{75}$ por cualquier territorio cristiano al que fueran conducidos. Sin ninguna duda, esta práctica, a la que se obligaban mediante solemne juramento, pretendía que el testimonio de los liberados, narrando los ingentes tormentos padecidos durante su cautividad, conmoviera a la audiencia y propiciara el ejercicio de la caridad $^{76}$. Las procesiones y actos religiosos, con participación de todo el clero del lugar, que se celebraban cuando una expedición redentorista regresaba con los cautivos no dejan de ser, asimismo, actos de propaganda ${ }^{77}$.

\footnotetext{
70. REYNÉs, Lorenzo: op. cit. f. 56 r.

71. Citado por Díaz BorRás, Andrés: op. cit. pp. 30-31.

72. BRODMAN, James William: «Captives or Prisoners...», p. 215.

73. Ferrer Mallol también presenta estas reservas. FerRer MALLOL, Maria Teresa: «La redempció de captius...», p. 273. Véase la magistral aportación de ATIENZA LóPEZ, Ángela: «Las crónicas de las órdenes religiosas en la España Moderna. Construcciones culturales y militantes de época barroca», en ATIENZA LóPEZ, Ángela (ed.): Iglesia memorable. Crónicas, historias, escritos... a mayor gloria. Siglos XVI-XVIII. Madrid, Sílex, 2012, pp. 25-50.

74. Mut i Armengol, Vicente: op. cit. p. 531.

75. Menos de dos meses, según Ruiz Barrera, María Teresa: «Redención de cautivos. Una especial obra de misericordia de la Orden de la Merced», en CAmpos y Fernández de SeVILLA, Francisco Javier (coord.): La Iglesia española y las instituciones de caridad. San Lorenzo del Escorial, Real Centro Universitario Escorial-María Cristina, Ediciones Escurialenses, 2006, p. 844.

76. Pascual, Eusebio: op. cit. pp. 123-126; Brodman, James William: «Community, Identity...», p. 249.

77. Ruiz Barrera, María Teresa: op. cit. pp. 845-846.
} 


\section{EL CLERO SECULAR COMO ORGANISMO REDENTOR}

A pesar de que la acción de los frailes redentoristas es la más conocida, el clero secular también tuvo un rol fundamental en el rescate de los cristianos. Tanto la catedral como el resto de parroquias de la diócesis de Mallorca contaban con un bacín cuyo contenido se destinaba a la redención de los cautivos en manos de musulmanes. De acuerdo con la práctica habitual, cada cepillo era confiado a un bacinero - generalmente un laico- que se encargaba de la recolección de las limosnas depositadas por los fieles, ya fuera por voluntad espontánea, ya fuera animados por la predicación ${ }^{78}$. La recaudación de los bacines de toda la diócesis era depositada periódicamente en un arca común. Una comisión integrada por el obispo, el Cabildo catedralicio y los jurados de Mallorca tenía la facultad de abrir la caja de la recaudación y distribuir el monto que se hallara entre los diferentes cautivos. La parte correspondiente a cada uno dependía no solo del dinero que hubiera en el arca, sino también de la calidad de los prisioneros o de aquellos que intercedieran por ellos ${ }^{79}$. En diciembre de I45I, la comisión se reunió en la casa nova capitular de la Seu. En la sesión asistieron dos jurados, Guillem de Puigdorfila i Antoni Sartre, y seis canónigos: Jordi Gual (deán), Joan Umbert, Nicolau de Montalt, Joan Borràs, Pere Gual y Francesc Sala. Los reunidos procedieron a repartir las noventa y dos libras y seis sueldos que se habían hallado en el arca, procedentes de los bacines de la catedral y de las parroquias. En el documento se consigna el nombre de los doce agraciados, así como la cantidad que se destinó a cada uno de ellos.

\begin{tabular}{|l|l|}
\hline Gabriel Figuerola & 10 libras \\
\hline Llorenç Buades & 7 libras y 10 sueldos \\
\hline Jaume Juan & 7 libras y 10 sueldos \\
\hline Nicolau Cassà & 14 libras \\
\hline Pere Climent y su hijo & 25 libras \\
\hline Bartomeu Saurina & 7 libras \\
\hline Joan Mateu & 7 libras y 10 sueldos \\
\hline Joan Serra & 5 libras \\
\hline Mateu Camps & 2 libras y 10 sueldos \\
\hline Jaume Costa & 2 libras y 10 sueldos \\
\hline Joan Patraqui & 2 libras y 10 sueldos \\
\hline Arnau Ferrer & 1 libra, 8 sueldos, 6 dineros \\
\hline Total & 92 libras, 8 sueldos, 6 dineros \\
\hline
\end{tabular}

TABLA 1. CAUTIVOS AGRACIADOS CON UNA LIMOSNA PARA SU REDENCIÓN (1451).

Fuente: ARM, AH, EU 9, f. 125 r-v.

78. La predicación podía mover el auditorio a la caridad. El rey Martín el Humano se preocupó de que el propio Vicente Ferrer mencionara en sus prédicas el caso de un cautivo mallorquín, Domingo Desprats, que estaba a punto de renegar. Ferrer MalloL, Maria Teresa: «La redempció de captius...», p. 240.

79. ACM, 1731, f. 5or: Lo die et any desús dits, los molt Reverent senyor bisbe, ensemps ab lo honorable Capítol e honorables jurats de la dita Universitat, [rayado: feren la partió] vistas las quantitats demunt scrites per rehudes dels acaptiris dels catius xhristians, fant entra aquells col-loqui e parlament, e fant sguart en la calitat dels detenguts e demanants, prossehiren concordantment en fer la partia e distribució de las dites quantitats en les persones devall scrites en la forma següent. 
En diciembre de I454, la comisión se volvió a reunir en la casa capitular de la Seu. En esta ocasión, asistieron los jurados - cuyos nombres no se refieren ${ }^{80}-\mathrm{y}$ ocho canónigos: Arnau de Marí (arcediano), Jordi Gual (deán), Francesc Eiximenis, Joan Borràs, Francesc Sala, Nicolau de Montalt, Miquel López y Gaspar Albertí. Esta vez, el monto fue suficientemente elevado como para ampliar la distribución hasta un total de diecinueve cautivos ${ }^{8 \mathrm{r}}$.

\begin{tabular}{|l|l|}
\hline Gabriel Figuerola & 5 libras \\
\hline Pere Climent y su hijo & 5 libras \\
\hline Bartomeu Saurina & 5 libras \\
\hline Joan Parra & 5 libras \\
\hline Mateu Camps & 2 libras y 10 sueldos \\
\hline Jaume Costa & 2 libras y 10 sueldos \\
\hline Arnau Ferrer & 5 libras \\
\hline Nicolau Jordi, hijo de Miquel Jordi & 8 libras \\
\hline Pau Moyà y su hijo Pere, bastardo & 15 libras \\
\hline Fra Bartomeu Sansó «Garí», carmelita & 2 libras y 10 sueldos \\
\hline Gabriel Tardà(?) & 7 libras y 10 sueldos \\
\hline Miquel Pons, de Porreres & 10 libras \\
\hline Bartomeu Suau & 2 libras y 10 sueldos \\
\hline Una mujer castellana o aragonesa & 2 libras y 10 sueldos \\
\hline Joan Ros, bracero de Mallorca & 20 libras \\
\hline Gabriel Ferrer & 10 libras \\
\hline Pau Pinya, cautivo en Granada & 20 libras \\
\hline Total & 128 libras \\
\hline
\end{tabular}

TABLA 2. CAUTIVOS AGRACIADOS CON UNA LIMOSNA PARA SU REDENCIÓN (1454).

Fuente: ARM, AH, EU 10, f. 119v.

Como se puede observar en las tablas precedentes, algunos cautivos - Gabriel Figuerola, Pere Climent y su hijo, Bartomeu Saurina, Mateu Camps, Jordi Costa y Arnau Ferrer- recibieron un subsidio de la comisión tanto en I45I como en I454. Este hecho se debe vincular al elevado rescate que se tenía que abonar para poder redimir a los cautivos, de modo que sus familiares y allegados se veían obligados a pedir ayuda durante años para poder reunir el monto exigido. También hay que remarcar que no todos los cautivos percibieron la misma cantidad. Esta variaba desde las veinticinco libras que se otorgaron a Pere Climent y a su hijo en I45I o las veinte libras de Joan Ros y Pau Pinya en I454, hasta la libra, ocho sueldos y seis dineros que se destinaron al rescate de Arnau Ferrer en I45I. Lo más probable es que esta diversidad se deba buscar en el distinto valor que los cautivos tenían, en función de su edad, sexo y estado de salud, lo que repercutía, asimismo, en

80. Los jurados de 1454 fueron Guillem de Sant Joan (caballero), Berenguer Talents y Joan Moix (ciudadanos), Pere Espanyol y Ramon de Moyà (mercaderes), y Lluís Prats (menestral). CAMPANER y FuerTes, Álvaro: Cronicón Mayoricense, Palma, Sa Nostra, 2007, p. 200.

81. ARM, AH, EU 10, f. 119v. 
el precio de su redención ${ }^{82}$. Esto podría explicar que se adjudicaran veinte libras al bracero Joan Ros, que, sin duda, debía contar con una buena condición física. Lamentablemente, el documento no ofrece descripciones detalladas de cada uno de los cautivos, lo que impide el establecimiento de una casuística que pudiera ayudar a relacionar la ayuda otorgada con determinadas características.

Los bacineros tenían derecho a destinar una pequeña cantidad de la colecta a los cautivos que desearan. Así sucedió, por ejemplo, en el caso de Guillem y Cristòfor Llinàs. El 6 de octubre de I442, el obispo, el Cabildo y los jurados dieron cincuenta libras al cirujano Jaume Canet para liberar a estos dos cautivos, a razón de veinte libras para Guillem y treinta para Cristòfor. Además de esta suma, el notario Bernat Pons, bacinero, añadió cinco libras más a la cantidad concedida para el rescate de Cristòfor Llinàs en virtud de la facultat a aquells atribuïda ${ }^{83}$. Del mismo modo actuó el honrado Joan Bartomeu, mercader, que regía el bacín de Santa Cruz, cuando añadió cinco libras a las veinticinco que recibió el marinero Joan Pruedes para redimir a Jaume Iscla, cautivo en Alger ${ }^{84}$. La verdad es que la comisión entregó también diez libras al propio Joan Bartomeu para que las destinara al rescate del sobredicho Jaume Iscla. En esta cantidad ya se incluían las cinco libras que Joan Desbrull había legado para la redención de cautivos cristianos en su último testamento ${ }^{85}$.

El 24 de noviembre de I44I, el obispo, el Cabildo y los jurados abrieron la caja en la que se custodiaban las donaciones para el rescate de los cautivos y hallaron dieciséis libras en ella. El prelado, entonces, añadió nueve más, hasta llegar a la suma total de veinticinco libras. Esta cantidad fue otorgada íntegramente al honorable Joan de Conilleres, ciudadano de Mallorca, para que pudiera rescatar al marinero Jordi Vaquer, igualmente mallorquín, retenido en Túnez, terra de moros. De acuerdo con lo dispuesto en los capítulos, Joan de Conilleres prometió devolver la cantidad concedida -incluso obligó sus propios bienes y se puso bajo el fuero del obispo- si el rescatado no regresaba a Mallorca en el plazo de seis meses ${ }^{86}$. Este intervalo de tiempo podía ser aumentado si era preciso. Así, Martí Basset dispuso de un año de margen para lograr la liberación de Antoni Ramon Salat; en caso contrario, tendría que devolver las diez libras a él asignadas ${ }^{87}$.

Este compromiso de devolver el dinero si no se redimía al cautivo indicado era adquirido normalmente por la persona que recibía el monto. Se conoce un caso en el que el juramento de reintegrar el subsidio si el rescate fracasaba fue prestado por menores de edad. El obispo, el Cabildo y los jurados destinaron veintidós libras al rescate de Julià Sastre, oriundo de Marratxí y cautivo en Alger.

82. Rodríguez Molina, José: op. cit. pp. 85-86.

83. ACM, 1731, f. 5 or.

84. Idem, f. $50 \mathrm{v}$.

85. Ibidem.

86. Idem, ff. $48 \mathrm{r}-\mathrm{v}$.

87. Idem, f. 68r: (...) dins hun any primer vinent traura lo dit Anthoni Ramon, o tornar les dites deu lliures. 
El dinero fue recibido por Jordi Fiol, Pere Sastre y Lluc Sastre. Estos dos eran de edad inferior a veinticinco años: Pere Sastre tenía veinte, mientras Lluc Sastre solo tenía dieciocho años. En todo caso, esto no supuso impedimento alguno para que prestaran el juramento acostumbrado ${ }^{88}$. Es posible que la presencia de Jordi Fiol en la recepción de la donación se debiera a la minoría de edad de los parientes directos de Julià Sastre.

Un poco menos documentado, pero para nada excepcional, era el caso de que el fiador del pago fuera una persona diferente de quien percibía la cantidad. Por ejemplo, el ro de junio de I467 Gabriel Lozano recogió las tres libras, diecisiete sueldos y cuatro dineros que el obispo, el Cabildo y los jurados habían decidido destinar al rescate de su hijo, también llamado Gabriel Lozano, cautivo en Bona. La persona que se comprometió a devolver el dinero si el joven Gabriel no regresaba a Mallorca al cabo de seis meses fue el mercader Joan Valleriola ${ }^{89}$. Es posible que los Lozano fueran una familia tan humilde que no pudieran afrontar la garantía, ni siquiera obligando sus bienes. En el caso que el dinero fuera entregado a un tercero, el compromiso también era transmitido con él. Así sucedió con las cuarenta y cinco libras que fueron dadas al cirujano Jaume Canet para rescatar a Guillem y a Cristòfor Llinàs. Cuando las recibió, Canet se obligó a devolverlas si la liberación no se llevaba a cabo. Poco después, las mismas cuarenta y cinco libras se entregaron al mercader Jaume Mollete, siempre con el objetivo de redimir a los predichos Guillem y Cristòfor Llinàs. Mollete también tuvo que prestar el juramento de reintegrar el dinero si no se usaba para la tarea a la cual se destinaba ${ }^{90}$.

Por norma general, los subsidios se concedían a plazos $^{9 \mathrm{I}} \mathrm{y}$ a fondo perdido, de modo que solo se recuperaba el monto en el caso de que la redención no tuviera éxito. A pesar de ello, a veces el dinero era devuelto aunque el rescate hubiera sido posible. Así, el i6 de diciembre de I44I el obispo, el Cabildo y los jurados entregaron a Bonifaci Morro, doctor en Decretos y también jurado, veinticinco libras que se tenían que destinar al rescate de Blai Riuclar, cautivo en Alger. Como era habitual, el doctor Morro juró devolver el dinero si Riuclar no regresaba a Mallorca al cabo de seis meses. El 2 de julio siguiente, Bonifaci Morro restituyó las veinticinco libras a Galceran Miró ante la presencia del notario Julià Pizà, de dos testigos y del propio Blai Riusec ${ }^{92}$. Se desconoce el motivo de este reembolso, puesto que la documentación no lo menciona.

Ya se ha indicado anteriormente que los familiares de los cautivos solían ser los encargados de gestionar la petición del subsidio. Los ejemplos de parientes recibiendo dinero de los jurados y del Cabildo catedralicio para redimir a allegados

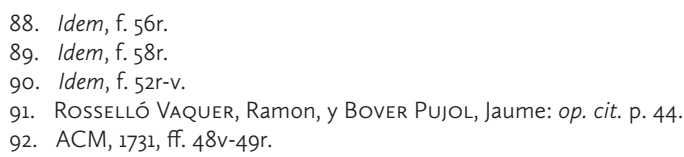


de diferentes grados son abundantes. Por ejemplo, Gabriel Lozano recibió una ayuda para rescatar a su propio hijo ${ }^{93}$, del mismo modo que también fue otorgado un subsidio para Guillem Llinàs gracias a los esfuerzos de su madre ${ }^{94}$. Por este motivo, los casos más problemáticos eran los que representaban las concesiones de auxilios a los cautivos que no tenían a nadie que pudiera recibir y gestionar el pago. Por ejemplo, el 28 de mayo de 1445 se otorgaron treinta libras para el rescate de Gabriel Llinàs, que se encontraba en Berbería. A pesar de ello, este no disponía de ningún contacto en Mallorca que pudiera recoger la ayuda. En consecuencia, las treinta libras fueron devueltas a la caja de los bacines, donde quedarían en depósito hasta que alguien las tomara para redimir al sobredicho Gabriel Llinàs ${ }^{95}$.

Los pagos no se ofrecían siempre a personas en cautividad, sino que, a veces, la comisión integrada por el obispo, el Cabildo y los jurados podía otorgar la cantidad a antiguos cautivos que ya habían sido liberados. Este hecho puede parecer sorprendente, pero está altamente documentado. Como indica Ferrer Mallol, era habitual que un cautivo fuera liberado antes de pagar todo su rescate, ya fuera porque alguien había avanzado el dinero, ya fuera porque había dejado un rehén ${ }^{96}$. En ambos casos, el cristiano estaba obligado a terminar de abonar el pago, y los poderes municipales y eclesiásticos continuaron ayudándolo con los pertinentes subsidios. Así, el 3 de diciembre de 1466 se dieron siete libras a Antoni Bolitxer; la suma fue recogida por el propio cautivo el i6 de abril de $1467^{97}$.

A pesar de los intentos para redimir a los cautivos cristianos, a veces estos morían antes de poder ser rescatados. Este fue el caso de Joan Company, que estaba retenido en Túnez. El obispo, el Cabildo y los jurados otorgaron treinta libras al pelaire Miquel Domingo para que lo rescatara. Además, el bacinero de Santa Eulalia, Joan Amades, añadió cinco libras a la suma. Desgraciadamente, Company había fallecido en tierra de moros. Las treinta y cinco libras, entonces, fueron entregadas a la madre de Guillem Llinàs para el rescate de su hijo ${ }^{98}$. Se dio un caso similar con las treinta libras que el mercader Lluís Pardo había recibido el 3 de octubre de I444 para rescatar al yerno de Nicolau Genovard. Pardo afirmó que el cautivo había muerto antes de poder ser rescatado, por lo que el mercader reembolsó las treinta libras al Cabildo el 5 de diciembre de I446, dos años después de su concesión ${ }^{99}$. Otro ejemplo son las veintidós libras que habían sido otorgadas a Joan Dita, que fueron luego destinadas al marinero Bernat Julià, puesto que el predicho Dita había muerto en cautividad. Sin embargo, Julià ya había sido redimido cuando se le entregó el dinero, así que decidió repartir la suma

93. Idem, f. 58 r.

94. Idem, f. 52 r.

95. Idem, f. 54 r.

96. Ferrer Mallol, Maria Teresa: «La redempció de captius...», pp. 254-255.

97. Idem, f. 57 r.

98. ACM, 1731, f. 52 r.

99. Idem, f. 55 r. 
entre el pelaire Joan Gabriel y fray Salvador Siurana, ambos todavía en poder de los musulmanes ${ }^{\mathrm{IoO}}$. En el caso de Pere Cunill, un joven de veinte años de Pollença que estaba cautivo en Bona, se le otorgaron tres libras, diecisiete sueldos y cuatro dineros, pero es posible que estas cantidades no llegasen a serle entregadas, puesto que llegó la noticia que había fallecido. Así, el escribano capitular se limitó a rayar la concesión con la macabra indicación mortus est ${ }^{\mathrm{IOI}}$.

De todos modos, la peor situación que se podía dar era que el cautivo renegara de la religión cristiana y abrazara el Islam. Este hecho supondría la inmediata liberación del converso, pero, desde el punto de vista de la Iglesia, también su perdición ${ }^{\mathrm{IO2}}$. El peligro era elevado y frecuentemente esgrimido a la hora de pedir dinero para el rescate, como lo hizo doña Anneta ${ }^{\mathrm{I0}}$. Por este motivo, la actividad redentorista se convirtió en una prioridad para la Iglesia. Incluso se tendrían que reembolsar los subsidios otorgados para el rescate de un cautivo en el caso de que este hubiera dejador de seguir a Cristo. Así, en diciembre de I454, Daniel Pinya se comprometió a devolver a los jurados y a los canónigos de Mallorca las veinte libras que se le adjudicaron para rescatar a Pau Pinya si este moría, era liberado o renegaba del Cristianismo antes de que se llevara a cabo la redención ${ }^{104}$.

Pero también hubo algunos casos - los menos ${ }^{105}$ - que finalizaron con éxito. El marinero Jaume Cabessa había estado cautivo en Bugía, pero pudo abandonar la cautividad gracias a una donación de veintisiete libras procedentes de los bacines. Cabessa regresó a Mallorca, y el I4 de mayo de 1448 reconoció haber recibido, además de las susodichas veintisiete libras, tres libras y diecisiete sueldos más en diciembre de $1446^{\mathrm{ro}}$. Los testimonios de este reconocimiento fueron los presbíteros Antoni Bassa y Antoni Salat, el mercader Guillem Llinàs y el jurado Antoni Nadal ${ }^{107}$. Cabe destacar que tanto Antoni Bassa como el mercader Llinàs también habían sido cautivos redimidos. Igualmente exitoso fue el rescate de Jaume Vicens, que estaba cautivo en Bugía. El 27 de noviembre de 1445 le fueron destinadas veinte libras, que fueron recogidas por Pere Vidal, Andreu Alegret y

100. Idem, sf.

101. Idem, f. 57 r.

102. Ferrer Mallol, Maria Teresa: «La redempció de captius...», pp. 239-240; DíAz Borrás, Andrés: op. cit. p. 18; BRODMAN, James William: «Captives or Prisoners...», p. 213.

103. ACM, Papeles y cuadernos sueltos, 16.298, sf.: (...) son marit, que és catiu en Barbaria e stà en perill de negar la sancta fe catòlica (...).

104. ARM, AH, EU 10, f. 119v: (...) promès que si per vetura lo dit Pau Pinya no exia de la dita captivitat, sò és que morís ans que isqués o's renegans, sò que Déu no vulla; e axi matex si seguia o exia sens pagar rescat, de tornar e restituir les dites vint libras al dit Pau adiudicades per son rescat, segons demunt és contengut, en mans dels honorables jurats e honorables canonges sens alguna dilació.

105. Brodman, James William: «Community, Identity...», p. 252; BrodmAN, James William: «Captives or Prisoners...», p. 219. 106. ACM, 1731, f. 56r: Postea vero die sabbati, XIII die mensis maii anno a nativitate Domini $M^{\circ} \mathrm{CCCLXVIII}^{\circ}$, prefatus Jacobus Cabessa, presens in Maioricis, in presentia notarii et testes, confessus fuit commisse predictas viginti septem libras unacum tribus libras et decem septem solidis sibi [rayado: ad] postea adjudicatis sub die mercurii, tertia mensis decembris anno a nativitate Domini $M^{\circ}$ CCCCLXVI .

107. Ibidem. 
Miquel Aulet el 26 de septiembre de I447. El I2 de mayo de I448 Jaume Vicens ya había regresado a Mallorca ${ }^{\mathrm{I} 8}$.

Como se ha indicado, buena parte de los recursos destinados a la redención de cautivos procedía de los testamentos. Eran muchos los cristianos que se acordaban de los prisioneros en manos islámicas en el momento de redactar sus últimas voluntades. Es muy habitual encontrar legados al bací dels catius, aunque sus cantidades solían ser muy escasas como resultado de una elevada fragmentación de la parte de la herencia asignada a mandas pías $^{109}$. Los legados eran efectuados por los albaceas testamentarios. No todos los cumplimientos de las disposiciones eran rápidos: una nota indica que el ciudadano Pere Brondo debía cien libras a la caxa dels catius christians en ejecución del legado que había dejado su hermano Jaume Brondo en su último testamento ${ }^{\text {IIO }}$. Las últimas voluntades solían ser genéricas y se limitaban a dejar una cantidad para la liberación de los prisioneros, sin indicación de más detalles. Fue el caso de Pere Amat, que en I330 legó dos sueldos para la redención de cautivos ${ }^{\mathrm{III}}$. Sin embargo, a veces se encuentran algunas referencias a legados nominativos. Así, el día II de marzo de i467 el mercader Francesc Homar entregó diez libras que Isabel, mujer de Bernat Serra, había legado en su testamento. Con esta entrega, su hija, Clara Serra, casada con Joan Mercer, había dado cumplimiento al deseo de su madre. A pesar de ello, Clara y su marido pidieron que, en el momento de distribuir la colecta, las diez libras fueran destinadas a la redención del marinero Antoni Bolitxer ${ }^{\mathrm{II} 2}$. Si bien esta finalidad no aparece en el testamento de la difunta, no deja de ser una evidencia del interés de algunas personas en controlar las distribuciones del arca de los bacines.

\section{ASPECTOS SOCIOLÓGICOS DE LOS CAUTIVOS}

Tras conocer los mecanismos existentes para la liberación de los cautivos y su aplicación por parte de la Iglesia de Mallorca, se propone, en las siguientes páginas, avanzar hacia una primera prosopografía de los cristianos que fueron redimidos por ella ${ }^{\mathrm{II}}$. La escasez de datos de los que se dispone no permite profundizar en este aspecto, aunque sí que se cuenta con cierta información que posibilita arrojar una primera luz al grupo de los cautivos como un colectivo y destacar los elementos que comparten entre sí.

108. Idem, f. $56 \mathrm{v}$.

109. TORRES JIMÉNEZ, Raquel: op. cit. p. 170.

110. ACM, 1731, f. 59v.

111. $A C M, 14.551$, f. $63 v$.

112. ACM, 1731, f. 58v. Véase, también, Brodman, James William: «Community, Identity...», p. 251.

113. Para la prosopografía, véanse StONE, Lawrence: The Past and the Present revisited. Londres, Routledge \& Kegan Paul, 1987, pp. 45-73; VONES-LIEBENSTEIN, Ursula: «El método prosopográfico como punto de partida de la historiografía eclesiástica», Anuario de Historia de la Iglesia, 14 (2005), pp. 351-364. 
Antes de entrar en aspectos personales, es interesante saber dónde eran conducidos los cristianos apresados. La mayoría eran cautivos en el norte de África, llamado comúnmente «Berbería». Este espacio englobaba sitios como Argel, Bona, Bugía o Túnez, lugares en los que es frecuente hallar cristianos cautivos. Sin embargo, también hay casos de otros destinos. Por ejemplo, Pau Pinya se encontraba prisionero en Granada ${ }^{\mathrm{II} 4}$, mientras el yerno de Genovard pasaba sus días en Atenas $^{115}$. A pesar de que el Islam preveía la redención como un acto inmediato a la captura de los cristianos - una cautividad a largo plazo ya implicaba el paso a la esclavitud-, Berbería, así como Granada, contemplaban la posibilidad de mantener a los cristianos cautivos durante años. Esto se debía al hecho de que tanto el norte de África como el reino nazarí eran territorios de frontera inmediata, de modo que se necesitaban grandes sumas de dinero para destinarlas a la defensa. Una de las fuentes de recursos eran, pues, los rescates de los cristianos cautivos ${ }^{\mathrm{II}}$.

La documentación no aporta datos sobre las condiciones de la cautividad de los cristianos, aunque es muy probable que esta información se mencionara en las peticiones de ayuda. Fuentes de otros lugares sí que indican las penalidades por las que pasaban los cautivos. Por ejemplo, en un documento de finales del siglo XIv procedente de Gerona se explica que los cristianos sufrían de detención, hambre, sed, desnudez, frío y calor, además de ser sometidos a latigazos y encadenados con grilletes de manos y pies; todos estos sufrimientos lo asemejaban a un mártir por la fe $\mathrm{fi}^{\mathrm{II}}$. La verdad es que la situación del cautivo no-musulmán estaba regulada por la ley islámica. Para empezar, solo podía ser considerado un cautivo legítimo aquel que hubiera sido hecho prisionero en el marco de una guerra igualmente legal ${ }^{118}$. En este caso, el captor tenía derecho a esclavizarlo, a ofrecerle la oportunidad de reunir el dinero necesario para pagar su rescate, o a matarlo, siempre después de haberlo invitado a convertirse al Islam ${ }^{\mathrm{II}}$. Si los prisioneros habían sido apresados al margen de una guerra, aquellos que se mostraran peligrosos tenían que ser ejecutados, mientras los otros debían poder aspirar a su redención. Numerosos pensadores islámicos se preocuparon de analizar el status

114. ARM, AH, EU 10, f. 119v.

115. ACM, 1731, f. 55r. Atenas se encontraba bajo el poder de los otomanes desde 1456.

116. Brodman, James William: «Captives or Prisoners...», pp. 205-206. La práctica de respetar la vida de los cautivos no se daba solo entre los musulmanes, sino también entre los cristianos de la península lbérica. Su no comprensión fuera de este territorio dio lugar a episodios como las masivas deserciones de mercenarios, que optaban por matar a los cautivos. Calderón Ortega, José Manuel, y Díaz González, Francisco Javier: «El rescate de prisioneros...», p. 47.

117. Sierra Valentí, Eduard: op. cit. p. 388; Ferrer Mallol, Maria Teresa: «La redempció de captius...», p. 239. Véase, igualmente, CAlderón Ortega, José Manuel, y Díaz González, Francisco Javier: Vae Victis..., pp. 127-127-136, especialmente pp. 131-132; Rodríguez MolinA, José: op. cit. pp. 88-89 y, para el concepto de mártir, 171-172.

118. Idem, pp. 84-85.

119. Los musulmanes que capturaban a cristianos podían resolver de cinco maneras: matarlos, liberarlos, esclavizarlos, permitir su rescate o imponerles el pago de la yizya. Calderón OrTega, José Manuel, y Díaz González, Francisco Javier: Vae Victis..., p. 123. 
de los prisioneros y toda la casuística que la cautividad suscitaba, como puso de manifiesto Brodman en una excelente aportación ${ }^{120}$.

La práctica totalidad de los cautivos eran hombres. Este aspecto tiene fácil explicación si se tiene presente que buena parte de las capturas tenían lugar en alta mar, y que la tripulación de los navíos estaba formada por varones. La presencia de mujeres se limitaría, pues, a posibles pasajeras ${ }^{121}$. En el caso de que los cristianos fueran apresados en el marco de un asalto costanero, el número de hombres y de mujeres sería más cercano. Las referencias a cautivas en los registros analizados son escasas, aunque existentes. Básicamente, se trata de la mujer de origen incierto a quien se concedieron dos libras y media en $\mathrm{I} 454^{\mathrm{I2} 2}$.

Es igualmente destacable el hecho que muchos cristianos fueron apresados junto a sus hijos. Los ejemplos abundan entre los ya mencionados hasta el momento, como el de Pere Climent, que recibió veinticinco libras en I45I y cinco más en I454 para pagar su rescate y el de su hijo ${ }^{\mathrm{I23}}$. No se trata de un hecho sorprendente, habida cuenta de que algunos hijos de mercaderes o marineros acompañaban a sus padres en sus viajes para aprender el oficio. Además, ya se ha indicado que, a veces, los musulmanes atacaban las costas cristianas y se llevaban a los vecinos que hallaban, de modo que familias enteras podían ser sometidas a cautiverio ${ }^{\text {I24 }}$. También es curioso el caso de Pau Moyà y de su hijo bastardo, Pere, que, a pesar de la ilegitimidad de este, recibieron conjuntamente un subsidio de quince libras ${ }^{125}$.

Por lo que se refiere a los hombres de Iglesia, no son muy habituales las noticias de sus capturas, a pesar de que también viajaban entre Mallorca y el continente, a veces para cumplir con sus obligaciones, como las visitas ad limina. En los registros analizados, hay que destacar el hallazgo de un carmelita, fray Bartomeu Sansó. El monto que se le entregó para su redención fue muy escaso, solo dos libras y media $^{\text {I26 }}$. También se mencionan un clérigo, Pere Carbonell, y Vicenç Bisbal, presbítero, a los que se entregaron cinco y diez libras, respectivamente ${ }^{\mathrm{I27}}$. No se puede dejar de lado tampoco la cautividad de fray Salvador Siurana, ermitaño, llevado a Bona $^{128}$. La parca información que el documento ofrece sobre ellos imposibilita conocer las circunstancias exactas de su aprisionamiento.

Los orígenes geográficos de los cautivos son bastante desconocidos, aunque a veces hay alguna indicación de este tipo. Por ejemplo, se duda de la procedencia castellana o aragonesa de una cautiva — de lo que se deduce que hablaba en

120. Brodman, James William: «Captives or Prisoners...», pp. 204-206. También CaLdERón OrTEGA, José Manuel, y Díaz GonzÁlez, Francisco Javier: Vae Victis..., pp. 67-68.

121. Rodríguez Molina, José: op. cit. p. 84.

122. ARM, AH, EU 10, f. 119v.

123. ARM, AH, EU 9, f. 125r; ARM, AH, EU 10, f. 119v.

124. Se citan varios casos en Ferrer MALlol, Maria Teresa: «La redempció de captius...», pp. 278-282.

125. ARM, AH, EU 10, f. 119v.

126. Ibidem.

127. ACM, 1731, f. 51 r

128. Idem, f. 59 r. 
castellano-, y también se menciona que Joan Ros era mallorquín. Más concreta es la referencia a Pere Cunill, de quien se especifica que era de Pollença ${ }^{\mathrm{I2} 9}$, un pueblo al norte de la isla que sufrió largamente las incursiones de los corsarios. Precisamente, la mayor parte de los mallorquines que fueron reducidos a la cautividad eran de pueblos cercanos al $\operatorname{mar}^{130}$. A este efecto, hay que destacar que en I44I se otorgaran subsidios a un total de siete habitantes de Sóller, una villa abocada al mar ${ }^{131}$. Esta elevada presencia de sollerics en cautividad es indicativa de un asalto al pueblo o a una nave procedente de su puerto. Un poco más curioso es el caso de Miquel Pons, que era de Porreres ${ }^{132}$. No se conocen sus otras circunstancias personales, aunque serían muy interesantes, puesto que Porreres es un pueblo del interior de Mallorca.

A pesar de que los datos son escasos, se puede observar con facilidad una tendencia a que los cautivos rescatados - especialmente aquellos que se beneficiaron de un subsidio concedido por los jurados y el Cabildo- fueran habitantes de la propia diócesis. La idea era que el dinero del obispado tenía que ir destinado a los cristianos bajo el dominio episcopal de Mallorca. Este era el principio de los rescates: baste notar que en I45I los jurados concedieron al mercader Pere Alborns lo bassí d'argent del catius christians de la present illa de Mallorca que había en la parroquia de Santa Eulalia, ${ }^{133}$ hecho que demuestra que las limosnas que se depositaran en aquella caja sería solo destinados al rescate de personas de una geografía específica. El fenómeno ha sido largamente notado en sus varios niveles por Brodman, que fija como fecha de inicio de esta tendencia los años centrales del siglo xill, cuando los cautivos dejaron de ser prisioneros de guerra y pasaron a ser capturados en las travesías marítimas ${ }^{134}$. Los monarcas partían de la misma premisa que los prelados. Por este motivo, cuando Gregorio XI expidió una bula concediendo una indulgencia a todos aquellos que donaran una limosna para los cautivos en 1377, Pedro el Ceremonioso temió que la Santa Sede centralizara los rescates y prohibió que el dinero de la Corona de Aragón saliera de sus reinos ${ }^{135}$.

Si el origen de los cautivos es escasamente conocido, su oficio no es tampoco más noto. Sin tomar en consideración los religiosos, se mencionan pocos empleos. Sin duda alguna, la mayoría de capturados se dedicaría a profesiones marítimas, como pescadores y marineros en sentido amplio; este era el caso de Jordi Vaquer o de Joan $\mathrm{Cabessa}^{\mathrm{13} 6}$, así como de seis cautivos redimidos por los mercedarios en $\mathrm{I}_{4} \mathrm{I}^{\mathrm{I} 37}$. Esto se explica porque aquellos que tenían que estar viajando constantemente o que

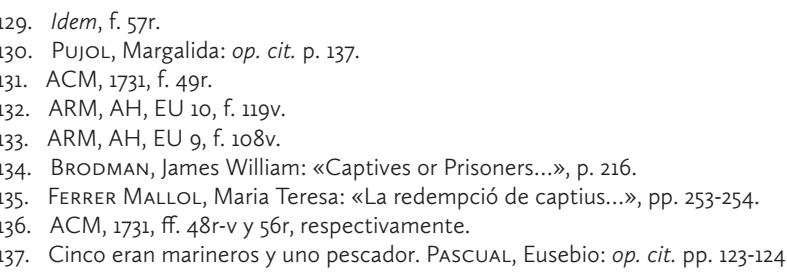


faenaban en el mar estaban siempre más expuestos a los asaltos de los corsarios musulmanes ${ }^{138}$. Hay que destacar que no se mencionan mercaderes propiamente dichos, quizá porque los comerciantes solían disponer de un salvoconducto que protegía sus personas y sus bienes ${ }^{139}$. Respecto a los cautivos cuyas profesiones no estaban ligadas al mar, abundan los braceros. De nuevo, de los veintiocho redimidos por los mercedarios, seis se dedicaban a este oficio, mientras otro era cuchillero y otro botero $^{\mathrm{I} 4 \mathrm{O}}$. La ausencia de otros datos impide formular hipótesis al respecto.

\section{CONCLUSIONES}

La cautividad era un riego cotidiano en las zonas de frontera y en el mar ${ }^{141}$. Los habitantes de las zonas costaneras y aquellos que se dedicaban a profesiones marítimas tuvieron que aprender a convivir con el peligro y ser conscientes de que podían caer prisioneros en cualquier asalto sarraceno. Por el hecho insular, la diócesis de Mallorca estaba especialmente expuesta a los ataques de los musulmanes. Muchos mallorquines fueron hechos cautivos y llevados, principalmente, a las regiones de Berbería, donde esperaron su redención mediante los sistemas institucionalizados. La Iglesia mallorquina no abandonó a sus fieles y participó en las campañas de rescate, ya fuera otorgando ayudas y subsidios a los cautivos o a sus familiares, ya fuera protagonizándolas en el caso de los frailes redentoristas. En cualquier caso, siempre se dependió de la caridad de los cristianos, que se manifestaba en forma de limosnas o legados testamentarios.

El hecho más destacable que se ha puesto de relieve en este artículo es la colaboración entre las autoridades municipales y el clero secular mallorquín por lo que se refiere a la distribución del monto del arca, que se nutría con las cantidades depositadas en los bacines que había repartidos en la catedral y en las diferentes parroquias del obispado. Era habitual que fueran las autoridades municipales las que otorgaban subsidios entre los cautivos que residían en su término ${ }^{\mathrm{I} 22}$. En cambio, en el caso de Mallorca, se observa una completa simbiosis entre los jurados y los canónigos de la catedral, puesto que ambos colectivos integraban la comisión que se encargaba de distribuir el dinero. Es posible que este hecho se deba a la jurisdicción que los jurados tenían sobre todo el Reino de Mallorca ${ }^{143}$, un territorio dentro del cual se integraba toda la diócesis.

\footnotetext{
138. RodRIGUEZ, Jarbel: Captives and Their Saviors..., p. 13.

139. Idem, p. 16.

140. Pascual, Eusebio: op. cit. pp. 123-124.

141. Rodriguez, Jarbel: Captives and Their Saviors..., pp. 1-2.

142. Este fue el caso de Valencia en 1323. Brodman, James William: «Captives or Prisoners...», p. 214. También los municipios castellanos procuraban el rescate de sus vecinos cautivos, puesto que su situación era consecuencia de la defensa de la ciudad. Calderón Ortega, José Manuel, y Díaz González, Francisco Javier: Vae Victis..., p. 167.

143. Planas Rosselló, Antonio: Los jurados de la Ciudad y Reino de Mallorca (1249-1718). Palma, Lleonard Muntaner, Editor, 2005, pp. 10-12.
} 
De hecho, se ha constatado la importancia que la procedencia geográfica tenía en la redención de los cautivos. Se ha podido notar que la inmensa mayoría de los cristianos rescatados, tanto por las órdenes religiosas como por la comisión de jurados y canónigos, eran de los territorios que conformaban la Corona de Aragón. Este hecho está muy bien documentado para las órdenes redentoristas, y, sobre todo, para la Orden de la Merced. No hay que olvidar que los mercedarios contaban con el apoyo real y que estaban muy ligados a la Corona; incluso, llegaron a financiar las expediciones guerreras del monarca al norte de África con las limosnas destinadas a los rescates ${ }^{\mathrm{I} 4}$. El caso de los subsidios otorgados por la comisión de jurados y canónigos es todavía más significativo, puesto que, en este caso, la inmensa mayoría de redimidos eran mallorquines: a excepción de la mujer castellana o aragonesa, no se documentan subsidios a otros forasteros.

Igualmente importante a la hora de distribuir el dinero era el aspecto social. Así, los cautivos que pertenecían a familias nobles o acomodadas, o que tuvieron a una persona de alto estamento que pudiera solicitar su rescate, tenían más facilidades para percibir una ayuda para su redención. Muchos de los perceptores directos del subsidio, frecuentemente intermediarios, fueron honorables -Joan de Conilleres-, ciudadanos, profesionales liberales - el cirujano Jaume Canet, el doctor en Decretos Bonifaci Morro- o mercaderes -Jaume Mollete, Lluís Pardo-, entre otros. Este hecho se debería a que eran personas con suficiente capacidad económica como para avalar el reintegro de la suma concedida en el caso de que el rescate no fuera exitoso. Además, muchas veces estos intermediarios estaban vinculados al comercio con el norte de África, y, por tanto, podían realizar los pagos para la redención de los cautivos. De hecho, el efectivo rescate de los cristianos era llevado a cabo por mercaderes o por los frailes redentoristas ${ }^{145}$. Sin embargo, otras personas con oficios aparentemente más humildes, como pescadores, zapateros, tejedores o pañeros, también recibieron subsidios para rescatar a sus allegados, lo que demuestra que cualquier persona podía solicitar el auxilio de jurados y canónigos.

No se observa ningún tipo de comunicación entre el clero secular y el regular en relación a la redención de cautivos. Trinitarios y mercedarios no formaban parte de la comisión de distribución de las limosnas. Además, solo se menciona una donación de cuarenta libras - realizada por el obispo, el Cabildo y los jurados-a los mercedarios para ayudarles en el rescate de cristianos apresados ${ }^{146}$. Este hecho constituye una evidencia de la separación entre las dos vías para redimir cautivos. Los jurados y los canónigos se dedicaron únicamente a distribuir el dinero del arca. En cambio, el rescate de los cristianos apresados por los musulmanes era el

144. BrodmAN, James William: «Community, Identity...», pp. 249-251.

145. Vaquer Bennàssar, Onofre: L'esclavitud a Mallorca. 1448-1500. Palma, Institut d'Estudis Baleàrics, Consell Insular de Mallorca, 1997, p. 71.

146. ACM, 1731, f. 6gr, 
elemento constitutivo más característico del carisma de trinitarios y mercedarios. Las órdenes redentoristas participaban en todo el proceso, desde la obtención de limosnas hasta la liberación de los cautivos.

Sin duda alguna, los mercedarios ostentaron la primacía en el rescate de los cristianos en la Corona de Aragón ${ }^{\mathrm{I} 47}$. Esta superioridad no solo se reflejó en el número de redimidos, sino también en las gracias y mercedes conseguidas. En I256 el arzobispo de Tarragona renunció a su prerrogativa de recibir el monto de las limosnas para distribuirlas entre los cautivos, tarea que fue cedida a la Orden de la Merced ${ }^{148}$. Los hijos de san Pedro Nolasco también lograron hacerse con el monopolio de la recaudación de las limosnas. Su poder se manifestó en el hecho de que consiguieron que Pedro el Ceremonioso derogara una autorización a los trinitarios que les permitía colocar bacines en iglesias y otros edificios públicos ${ }^{149}$. Los trinitarios, por su parte, tuvieron una mayor importancia en Castilla ${ }^{150}$, aunque esto no impidió que también socorrieran a los cautivos de la vecina Corona de Aragón.

En definitiva, los cristianos que caían en manos de los musulmanes sabían que tenían la oportunidad de liberarse del cautiverio. No era fácil: reunir el dinero para abonar el rescate era una misión que podía llevar años, y, frecuentemente, conducía a sus familiares a una situación de extrema vulnerabilidad. Pero los cautivos eran conscientes de la existencia de instituciones que velaban por ellos y que hacían lo posible para rescatarlos ${ }^{15 \mathrm{I}}$. El objetivo final no era otro que lograr que no desesperaran, que no renegaran del Cristianismo para abrazar el Islam y condenarse irremediablemente. Del mismo modo que Job, tenían que conservar la fe, a pesar de las adversidades, y esperar la redención. Solo de este modo serían verdaderamente liberados.

147. Brodman, James William: «Captives or Prisoners...», p. 215. Díaz Borrás plantea que el poco éxito de los trinitarios en la Corona de Aragón se explicaría por el hecho de que la Orden era francesa y había contado con el apoyo de Inocencio III, acérrimo enemigo de los cátaros, a cuyo favor luchó el rey Pedro el Católico. En otras palabras, la rivalidad en el Languedoc entre Francia y la Corona de Aragón supuso que los trinitarios fuesen vistos con recelo en este último territorio. Díaz Borrás, Andrés: op. cit. pp. 40-41.

148. Brodman, James William: «Captives or Prisoners...», p. 214.

149. SAnCho, Pedro Antonio: op. cit. pp. 397-399; FerRer Mallol, Maria Teresa: «La redempció de captius...», pp. $271-272$.

150. Brodman, James William: «Captives or Prisoners...», p. 215.

151. Díaz Borrás, Andrés: op. cit. p. 39. 


\section{BIBLIOGRAFÍA}

Atienza López, Ángela: «Las crónicas de las órdenes religiosas en la España Moderna. Construcciones culturales y militantes de época barroca», en ATıEnza López, Ángela (ed.): Iglesia memorable. Crónicas, historias, escritos... a mayor gloria. Siglos XVI-XVIII. Madrid, Sílex, 20I2, pp. 25-50.

Ayala Martínez, Carlos de: «Órdenes militares hispánicas: reglas y expansión geográfica», en García de Cortázar, José Ángel, y Teja, Ramón (dirs.): Los monjes soldados. Los templarios y otras órdenes militares. Aguilar de Campoo, Fundación Santa María la Real, 2004 [I997], pp. 57-86.

Ayala Martínez, Carlos de: Las órdenes militares hispánicas en la Edad Media (siglos XII-XV). Madrid, Marcial Pons, La Torre Literaria, 2007.

Barceló Crespí, Maria, y Ensenyat Pujol, Gabriel: Ferrando Valentí i la seva família. Barcelona, Universitat de les Illes Balears, Abadia de Montserrat, 1996.

Barceló Crespí, Maria, y Rosselló Bordoy, Guillem: La ciudad de Mallorca. La vida cotidiana en una ciudad mediterránea medieval. Palma, Lleonard Muntaner, Editor, 2006.

Brodman, James William: Ransoming Captives in Crusader Spain. The Order of Merced on the Christian-Islamic Frontier. Filadelfia, University of Pennsylvania Press, I986.

Brodman, James William: «Community, Identity and the Redemption of Captives: Comparative Perspectives across the Mediterranean», Anuario de Estudios Medievales, 36/I (2006), pp. 24I-252.

Brodman, James William: Charity \& Religion in Medieval Europe. Washington D.C., The Catholic University of America Press, 2009.

Brodman, James William: «Captives or Prisoners: Society and Obligation in Medieval Iberia», Anuario de Historia de la Iglesia, 20 (20II), pp. 20I-2I9.

Calderón Ortega, José Manuel, y Díaz González, Francisco Javier: «El rescate de prisioneros y cautivos durante la Edad Media hispánica. Aproximación a su estudio», Historia. Instituciones. Documentos, 38 (2011), pp. 9-66.

Calderón Ortega, José Manuel, y Díaz González, Francisco Javier: Vae Victis: cautivos y prisioneros en la Edad Media Hispánica. Alcalá de Henares, Universidad de Alcalá, 2012.

CAmpaner y Fuertes, Álvaro: Cronicón Mayoricense, Palma, Sa Nostra, 2007.

Cipollone, Giulio: Studi intorno a Cerfroid, prima casa dell'ordine trinitario (II98-I429). Roma, Ordinis Trinitarium Institutum Historicum, I978.

Cipollone, Giulio: «L'Ordo Trinitatis et captivorum. Il suo insediamento nelle Baleari (xillXIV)», en XIII Congrés d'Història de la Corona d'Aragó. Palma de Mallorca, 27 setembre-I octubre 1987. Palma, Institut d'Estudis Baleàrics, I989, III, pp. 37-45.

Cipollone, Giulio: Cristianità-Islam, cattività e liberazione in nome di Dio. Il tempo di Innocenzo III dopo il II87. Roma: Pontificia Università Gregoriana, 1992.

CONEJO DA PENA, Antoni: Assistència i hospitalitat a l'edat mitjana. L'arquitectura del hospitals catalans: del gòtic al primer renaixement. Barcelona, Universitat de Barcelona, (tesis doctoral inédita), 2002.

DíAz BORRÁs, Andrés: El miedo al Mediterráneo: la caridad popular valenciana y la redención de cautivos bajo poder musulmán, I323-I539. Barcelona, Consejo Superior de Investigaciones Científicas, Institución Milá y Fontanals, 200I.

FernÁNDEZ de Córdoba Miralles, Álvaro: «Sobre el encuentro del Cristianismo con el Islam en el Mediterráneo occidental», Anuario de Historia de la Iglesia, I6 (2007), pp. I5I-I55. 
Ferrer Mallol, Maria Teresa: «La redempció de captius a la Corona catalano-aragonesa (segle xiv)», Anuario de Estudios Medievales, I5 (1985), pp. 237-297.

Ferrer Mallol, Maria Teresa: «El castigo de los corsarios en el mundo mediterráneo medieval», en Guiance, Ariel, y Ubierna, Pablo (coords.): Sociedad y memoria en la Edad Media. Estudios en homenaje de Nilda Guglielmi. Buenos Aires, Consejo Nacional de Investigaciones Científicas y Técnicas, Instituto Multidisciplinario de Historia y Ciencias Humanas, 2005, pp. II9-I26.

Miralles Sbert, José: Catálogo del Archivo Capitular de Mallorca, vol. I. Palma, Imprenta «mossèn Alcover», I936.

Morro VenY, Guillem: La marina medieval mallorquina (I250-I450). Palma, Documenta Balear, 2009.

Mut i Armengol, Vicente: Historia del Reyno de Mallorca. Mallorca, I650.

Nieto Cerdà, Maria Magdalena: «El convent de la Mercè», en BARCeló Crespí, Maria, y Moll Blanes, Isabel (coords.): Abadies, cartoixes, convents i monestirs. Aspectes demogràfics, socioeconòmics $i$ culturals de les comunitats religioses (segles XIII al XIX). Palma, Institut d'Estudis Baleàrics, 2003, pp. 33-56.

O'CAllaghan, Joseph F.: A History of Medieval Spain. Ithaca, Cornell University Press, I975.

PASCUAL, Eusebio: «Redención y ostentación de cautivos. Siglos xill y xv», Bolletí de la Societat Arqueològica Lul.liana, 6 (I895), pp. I23-I26.

Planas Rosselló, Antonio: Los jurados de la Ciudad y Reino de Mallorca (I249-I7I8). Palma, Lleonard Muntaner, Editor, 2005.

Porras Arboledas, Pedro: «La obligación de rescatar cautivos y la Orden de Santiago (I5I7-I535)», Hispania Sacra, 69/139 (2017), pp. I95-2I9.

Pujol, Margalida: «L'esclavitud en el Regne de Mallorca durant el govern del Rei Martí I. I396-I4IO», Bolletí de la Societat Arqueològica Lul.liana, 52 (I996), pp. I29-I40.

Reynés, Lorenzo: Chrónica de la Provincia del Orden de la Santísima Trinidad Redención de Cautivos. Biblioteca Pública de Palma, ms. 47.

Rodriguez, Jarbel: Captives and Their Saviors in the Medieval Crown of Aragon. Washington D.C., The Catholic University of America Press, 2007.

Rodriguez, Jarbel: «Financing a Captive's Ransom in Late Medieval Aragon», Medieval Encounters, 9/I (2003), pp. I64-I8I.

RODRíguez Molina, José: La vida de moros y cristianos en la frontera. Alcalá la Real, Alcalá, 2007.

Rosselló VAquer, Ramon, y Bover Pujol, Jaume: «Captius cristians de Mallorca al nord d'Àfrica. Segle xv. Una relació», en GARcía Marín, Jesús (coord.): América y Mallorca. Del predescubrimiento hasta el siglo xx. Miscelánea humanística, I. Palma, Ajuntament de Palma, I99I, pp. 43-46.

Rubino, Antonio: L'Ordine di Santa Maria della Mercede (I2I8-I992). Sintesi storica. Roma, Istituto Storico, I997.

RUIz BARRERA, María Teresa: «Redención de cautivos. Una especial obra de misericordia de la Orden de la Merced», en CAmpos y Fernández de SEvilla, Francisco Javier (coord.): La Iglesia española y las instituciones de caridad. San Lorenzo del Escorial, Real Centro Universitario Escorial-María Cristina, Ediciones Escurialenses, 2006, pp. 84I-862.

SAlRach I MARÈs, Josep Maria: «Els orígens de l'Orde de la Mercè i el rescat de captius. Les Croades i l'exercici de la caritat a l'Edat Mitjana», Acta Historica et Archaeologica Mediaevalia, 9 (1988), pp. I89-20I.

Sancho, Pedro Antonio: «Redención de cautivos por los frailes trinitarios», Bolletí de la Societat Arqueològica Lul-liana, 8 (1900), pp. 336 y 397-399. 
SASTRE Moll, Jaime: «Los pobres y su asistencia hospitalaria en Menorca. La captación de limosnas por órdenes religiosas (s. xIv)», Bolletí de la Societat Arqueològica Lulliana, 57 (200I), pp. 49-6o.

Sierra Valentí, Eduard: «Captius de sarraïns. Llicències per a demanar caritat del bisbes de Girona (I376-I4I5)», Anuario de Estudios Medievales, 38/I (2008), pp. 385-428.

Stone, Lawrence: The Past and the Present revisited. Londres, Routledge \& Kegan Paul, I987.

TORRES JiMÉNEZ, Raquel: «Reflexiones sobre religiosidad medieval: el concepto de caridad en la espiritualidad laica, del amor a Dios al amor a los pobres, del mundo rural al humanismo», Cuadernos de Estudios Manchegos, 36 (2011), pp. I53-I84.

VAquer Bennàssar, Onofre: L'esclavitud a Mallorca. I448-I50o. Palma, Institut d'Estudis Baleàrics, Consell Insular de Mallorca, I997.

Vones-Liebenstein, Ursula: «El método prosopográfico como punto de partida de la historiografía eclesiástica», Anuario de Historia de la Iglesia, I4 (2005), pp. 35I-364. 
Calidad de Revistas

Científicas Españolas

FECYT|
AÑO 2019

ISSN: 0214-9745

E-ISSN 2340-1362

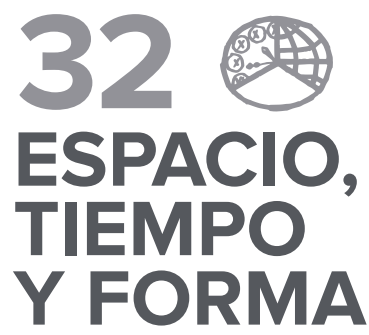

SERIE III HISTORIA MEDIEVAL

REVISTA DE LA FACULTAD DE GEOGRAFÍA E HISTORIA

\section{Artículos · Articles}

JoAquín Aparici Martí \& Concepción Villanueva Morte Deslindes y amojonamientos medievales en las serranías de Gúdar-Maestrazgo: un acercamiento al patrimonio rural y a la didáctica del territorio

\section{CARLOS BARQuero GoÑ}

Los hospitalarios y los monasterios en la Corona de Castilla durante los siglos XII y XIII

\section{Rocío BELLO GAY}

Representación política, oficios concejiles y acumulación económica en las aldeas abulenses en la Baja Edad Media: algunos apuntes acerca de la caracterización de las Ilamadas elites rurales (1474-1504)

105 Albert Cassanyes Roig Edad Media

La iglesia de Mallorca y la redención de cautivos en la Baja

133 Julián Clemente Ramos

Una dehesa por dentro: Castilrubio (1290-c. 1545). Paisaje, explotación y usurpación de términos

161 Francisco josé Díaz Marcilla

Las relaciones sociales dentro del Cancionero de Juan Alfonso de Baena (siglo XV). Redes y mentalidades

187 GUILLERMO FERnÁNDEZ ORTIZ

El archivo del monasterio cisterciense de Nuestra Señora de Belmonte (Asturias, España) en vísperas de la Reforma (1560)

\section{IVÁN GARCíA IZQUIERDO}

El linaje de Aza durante los siglos XIII y XIV: declive y resurgimiento

267 JAVier López RÍder

Migraciones rurales en el paisaje meridional del Reino de Córdoba en el tránsito de la Edad Media a la Moderna

303 Jesús Rodríguez Morales \& DAVID GonzÁlez Agudo
Los caminos de la repoblación segoviana en la Transierra entre los siglos XIII y XV a partir del Privilegio de las Alberguerías de 1273

337 Jonatan Romero Pérez el siglo XIV
Estructuras militares y logísticas en la Corona de Castilla durante
379 VICENT ROYO PÉREZ

Árbitros y mediadores en el mundo rural valenciano durante la Baja Edad Media: Els Ports y El Maestrat (s. XIII-XIV)

Xosé M. SÁNCHEZ SÁNCHEZ

Aproximación al concejo de la ciudad de Santiago de Compostela y su configuración entre los siglos XIII-XV. Un poder urbano en el señorío episcopal

\subsubsection{Fernando Serrano Larráyoz \& Manuel Francisco CARRILlo Rodríguez}

Nueva perspectiva acerca de las enfermedades de Enrique IV de Castilla: el recetario del doctor Gómez García de Salamanca

\subsection{Néstor Vigil Montes}

«Tractados de pazes, aliança e concordia entre as duas coroas de Portugal e Inglaterra», un cartulario realizado a comienzos del siglo XV para consolidar el Tratado de Windsor entre los reinos de Inglaterra y Portugal (1386), la alianza permanente más prolongada de la historia

\section{Notas de Filología castellana medieval · Notes of Medieval Castilian Philology}

(9) 1 Francisco Abad Nebot

Notas bibliográfico-críticas de Filología castellana medieval

\section{Libros · Books}

515 Arsuaga Laborde, Diego, Pedro Fernández de Velasco, primer conde de Haro. Un estudio de la figura de un ricohombre en la Castilla del Cuatrocientos (CARLOS BARQUERO GOÑI)

517 BECEIRO PITA, Isabel (directora), La espiritualidad y la configuración de los reinos ibéricos (siglos XII-XV) (ENRIQUE Cantera Montenegro)

529 Galende Díaz, Juan Carlos, Ávila SeoAne, Nicolás, El rodado regio hispánico: León y Castilla antes de la unificación (1157-1230) (MAURICIO HERRERO JIMÉNEZ)

533 IrIJOA Cortés, Iago, GoICOLEA Julián, Francisco Javier, García FERNÁNDEZ, Ernesto (coords.), Mercaderes y financieros vascos y riojanos en Castilla y en Europa en el tránsito de la Edad Media a la Moderna (Ana MARÍA Rivera MEdina) 


\section{2 -}

\section{ESPACIO,}

\section{TIEMPO}

\section{Y FORMA}

UกED

SERIE III HISTORIA MEDIEVAL

REVISTA DE LA FACULTAD DE GEOGRAFÍA E HISTORIA

\section{Libros · Books}

537 LACARRA, José María, Alfonso el Batallador. Estudio preliminar de Fermín Miranda (PAULINA LóPEZ PITA)

541 Martín López, María Encarnación y CaVero Domínguez, Gregoria, Colección Documental del Monasterio de San Guillermo de Villabuena (1172-1527) (JOSÉ MIGUEL LóPEZ VILLALBA)

545 Martín Prieto, Pablo, Las Cruzadas (Margarita Cantera MONTENEGRO)

547 Rı, Alice, Legal Practice and the Written World in the Early Middle Ages. Frankish Formulae, c. 500-1000 (AlEjANDRO PABLO BAÑón PARDO)

551 RoYo PÉrez, Vicent, Les arrels històriques de la comarca dels Ports. Societat, poder i identitat en una terra de frontera durant la Baixa Edat Mitjana (JULIÁN DONADO VARA)

555 SANTIAgo Fernández, Javier de, Política monetariay moneda en el reinado de Carlos II (José Miguel López VILLALBA)

559 Santiago Fernández, Javier de y Francisco Olmos, José María. de, Corpus Inscriptionum Hispaniae Mediaevalium. Guadalajara (11121499) (José Miguel López VILLALBA)

563 Solórzano Telechea, Jesús A. y Sousa Melo, Arnaldo (eds.), ZALACAIN) Trabajar en la ciudad medieval europea (ROBERTO J. GONZÁLEZ

567 Solórzano Telechea, J.A., Haemers, J., Czaja, R. (eds.), Exclusión y disciplina social en la ciudad medieval europea (MARÍA ÁlvareZ FernánDEZ)

571 TRANChant, Mathias, Les ports maritimes de la France atlantiMARTÍN PÉREZ) que $\left(X l^{e}-X V^{e}\right.$ siècle). Volume I: Tableau géohistorique (FERNANDO 